\title{
POPULATION DYNAMICS OF THE MAIN PELAGIC SPECIES EXPLOITED IN THE JAVA SEA: BIOLOGICAL PARAMETERS ESTIMATES
}

\author{
Bambang Sadhotomo*)
}

\begin{abstract}
Several sets of length frequency data (1991 to 1995) of the six species were used to estimate the growth parameters and to discuss the results in relation to possible influence of data structure on the parameter estimates. The von Bertalanffy growth parameters were well estimated using the Elefan routine and FordWalford method. The existing oscillation pattern and the pseudo growth progression curve were identified. It can be noticed that the estimated values do not represent the whole stocks. The emmigration of adult fishes is considered as the more important factor determining the shape of oscillation curve rather than that of the nature somatic growth pattern. More cohorts identified staying in the Java Sea during anomaly year consequently result a higher estimate values of $\mathrm{K}$ of certain species. The fish stock available for the fisheries mainly consists of young fishes, i.e. the average sizes of the main species are smaller than approximate length at first mature and very few specimens of adult fish were not available in the fishing ground all of the year. Two groups of recruits were identified, the major and the minor ones entered the fisheries during the Southeast and northwest monsoon, respectively The major recruits were not the offsprings descended by the adult fishes stayed in this area in last year period.
\end{abstract}

KEYWORDS: small pelagic, length frequency, growth, maturity, recruitment, Java Sea

\section{INTRODUCTION}

Biological study can be considered as the first stanza in understanding the population dynamics of the species. In the context of fisheries problems, these components of the dynamic system may not be analyzed separately. Nevertheless, separate analysis of the part of the system would be still valuable in explaining possible influence of the ecological dimension on the biological parameter. The parameter estimates of these component, i.e. growth, recruitment pattern and reproduction, will be evaluated in order to find possible reiation to ecological aspects and interaction with biological dimensions.

Due to the need of growth paramater estimates as input parameters for length based stock assessment models, several studies on the estimation on growth of pelagic species in the Java Sea have been conducted since the beginning of 1970's. Sujastani (1974) estimated the growth parameters of Rastrelliger kanagurta and $R$. brachysoma in Karimata Strait and Nurhakim $(1993 ; 1995)$ in the whole Java Sea for $R$. kanagurta. Dwiponggo et al. (1986) reanalysed the old data including five pelagic species, with no inspection on the validity of the data. We may cite also Suwarso et al. (1995); Sadhotomo \& Atmaja (1985) for four among the main species, and Widodo (1988b) for 2 species of Decapterus. Most of those studies were based on one year period of observations and there was no evaluation on the pattern of estimates to be done. In this study, several set of length frequency data (199.1 to 1995) of the main six species caught by purse seine fishery were used in attempting to estimate the growth parameters as input data for the model of stock evaluation.

\section{MATERIALS AND METHODS}

\section{Materials}

This study was mainly based on the length frequency measurement carried out in the years 1991 to 1995 and reproduction data of 1992 to 1993. Length frequency samples were collected from the seiners landed in Pekalongan, Juana, and Tegal. Compilation of the length composition data used in this study were listed in the tables of the document published by the Pelfish Project (Sadhotomo \& Potier, 1993; 1994; 1995; 1997). In order to obtain a proportional figure to the number of fishing boats operating in the fishing zones, the samples were systematically taken from the seiners berthing in harbors.

Six main species were chosen for representing the pelagic species in the Java Sea. These species contributed more than 85 percent of the total landing (Potier \& Sadhotomo, 1995), i.e. Decapterus russelli, D. macrosoma, Rastrelliger kanagurta, Amblygaster sim, Selar crumenophthalmus, and Sardinella gibbosa. 


\section{Length Composition Data Collection}

Sampling scheme was defined within Pelfish project for three main harbors, i.e. Pekalongan, Juana, and Tegal (Potier \& Sadhotomo, 1991) while general sampling procedure had been presented before the project implemented (Boely et al., 1990). The sampling was intended to gather the length frequency data and species composition by fishing zones and by purse seiners type. In this case, an assumption was done that catches or abundance be proportional to repartition of the fleet operating in the fishing zones.

In the field, 2 type of seiners, medium and big size of categories of boats were discriminated, since their operation pattern seemed to be different at the first three years of sampling activities. After 1994 the fishing ground of the two types tended to be similar, due to the increase of the size of the new boat of medium category. But, because the usage of old ones was still existing, separation of the categories could be expected to increase the accuracy of sampling. The fishing operation of the seiners landed in those harbors showed a similar pattern as well as their distribution of the length frequency of fish data (Potier \& Sadhotomo, 1995). For this reason, the data collected from the largest landing place (i.e. Pekalongan) would represent all harbours (Pekalongan, Tegal, and Juana).

For implementation of the sampling in the field, four surveyors were employed by the Pelfish worked for collecting these data under supervision of a scientific team. For clarifying the explanation about the sampling, details of the protocol were presented along the following paragraphs.

\section{Length Composition Sampling}

The sampling frame in this procedure was defined as the list of daily landings by seiners (i.e. 2 frames, one for medium size category and the other for the big size one), where sampling unit was the sample boat. The list consists of 1) the name of the seiners landed one day before in the afternoon until early in the morning in the same day; 2 ) type of boat; 3 ) the fishing zones; 4) information on the dominant catch; and 5) the type of preservation used (i.e.; ice or salt). Only the boats disembarking the fresh fish were taken as samples other wise they are considered as out of the frame.

If these were more than five boats coming from the same fishing zones, then 2 samples were systematically taken from the list with interval of 4 , other wise only one sample to be taken. The first sample was taken from the first order of this daily list. The second sample would be the second order if the boat was coming from another fishing zones. Otherwise second sample would be the fifth order if all of the boats coming from the same fishing ground. If the number of landings of the same zone were less than five, only one sample taken in a day. This procedure was applied separately to the big size and medium size of seiners. Detail of this procedure has been given by Potier \& Sadhotomo (1991).

In the next steps, one or two sub samples (a basket of fresh fish that is c.a. $30 \mathrm{~kg}$ ) were randomly taken from a fish hold of the sampling boat. The specimens were sorted into species and counted by species. Then the measurement was done for 50 or more fishes of each species if the species consisted of more than 50 fishes, otherwise all of specimens would be measured. The fork length measurement was done using measuring paper to $0.5 \mathrm{~cm}$ of accuracy. The data then to be transferred to a working sheet. A comparison on the composition of the sample by fishing grounds on the first six month of sampling shows that the samples were well represented in term of the distribution of the fishing zones prospected by the seiners. In this part, we did not perform any formal test to confirm the representation of the samples.

The monthly length frequency data then were pooled by species and fishing ground. A simple method of calculation for monthly summary was as follow. Let $x_{i j}$ is the frequency of species $i^{\text {th }}, j$ is the ${ }^{\text {th }}$ length interval. $N_{i}$ is number of fish measured of the species $i^{\text {th }}$ and equal to summation of $x_{i j}$, denoted as: $N_{i}=\sum x_{i j}$. Let $c_{i}$ is number of fish of species $i^{\text {th }}$ in a sub sample, then calculated frequency per sub sample by species would be $f_{i j}=x_{i j} . c / N_{i}$. This value then to be filled in the working sheet. Monthly compilation is done by summing $f_{i j}$ by fishing ground, that is $g_{i j k}=\sum f_{i j}$, where $k$ is index for fishing ground.

\section{Reproduction}

Regular samplings were conducted in Pekalongan and Juwana from August 1991 to December 1995. The observations cover the length, weight of body and gonads, stage of maturity and adiposity. Until end of 1991 no weight measurement was done. Only the data from the period 1992 to 1993 were used in this study. 
Subsamples were taken randomly from the fish holds of the seiners and immediately followed by sorting for separating the species. Special sampling were achieved several times for gathering mature fishes for microscopic description purposes. Specimens were dissected for gonads stages observation. The gonads were removed, and gross examination of the gonads were carried out by weighting and observing their shape and color visually. All aspects related to the sample are recorded in the working sheet such as name of the vessel, fishing zone, and some remarks concerning with biological observation.

\section{Methods}

\section{Growth}

Growth somatic parameters were estimated under the model of von Bertalanffy for entire and certain parts of the data. Concerning the coverage of the samples (i.e. fishing zones of the seiners), the usual restriction and assumption are exerted on this study, that is the growth estimates are only valid for the range of size or age being exploited by seiners or during their stay in the Java sea and not of their life span.

Two methods of estimations were performed, in order to reveal a possible periodical changes of growth parameters, as described in the following paragraph.

\section{Growth Estimation by Means of Cohort Modal Progression}

The means of length classes were estimated using a kind of graphical method (Bhattacharya, 1967) and then were confirmed through maximum likelihood estimation. The main objectives of the use of these methods are for decomposing the polymodal frequency or a mixture of normal distribution and estimating their means. Hasselblad (1966) introduced the maximum likelihood estimation using the log likelihood function for a multinomial distribution for estimating the parameter for a mixture of normal distribution. In the FISAT package program, it is called as the Normsep (stands for normal separation), This method usually give good parameter estimates, but the estimation procedure has a disadvantage for testing the statistical significance of likelihood ratio test and for estimating the covariance matrix of the estimates of parameter (Fournier et al., 1990). In this study, the use of this method was merely aimed for verifying the results of a preliminary estimation and not intended to further inference analysis.
Estimations of the mean length for symmetrical unimodal distribution would be easily determined from its mode. First trial using a maximum likelihood based software showed that the number of groups introduced at the starting point tended to be the same as the computation result. For this reason, rough estimation using other method (i.e. Battacharya method) prior to this method was aimed for having a more accurate estimates. The progression of the mean length of the same cohort could be traced by eyes or by following the growth line generated by elefan system. Then the growth parameter could be estimated for a single cohort only by ignoring minor distribution that do not describe a clear progression. Only the samples contribute to major cohorts were used in regression. In this step, the plotting of growth increment of unequal time interval were performed manually according to Gulland-Holt Plot (Gulland \&. Holt, 1967).

\section{Multiple Class Estimation}

ELEFAN routine was performed to estimate growth parameters. The growth curves produced by this method maybe used to trace modal class progression, and to define appropriate samples for being used in the next step which would clearly describe a progression. This procedure has an ability to estimate objectively the growth parameters from multiple length class represented in the data. But, it is based on ad hoc estimation procedure (Fournier et al., 1990), and its reliability could be doubtful in some cases and with certain data types.

This analysis works on restructured samples created by using certain standardized moving average. Restructurisation of the samples is a conversion of the ordinary length frequency data to the restructured ones which standardized to a new value being able to explain the strength of its probability. In this procedure, frequency of each class length is expressed in score reflecting the strength of its probability. The maximum value would indicate the means of distribution or the mode. In a set of length frequency data, sum of all positive scores (they may correspond to several peaks of the polymodal distribution) is denotes as available sum of peak, and the sum of scores or points associated with those, peaks in a set of length frequency data that are passed by a given von Bertalanffy's growth curve, is named as explained sum of peak.

Growth parameters were computed iteratively with maximizing the explained sum of peak being passed through by the growth lines. Detailed of the 
original version of elefan I procedure has been given in Pauly \& David (1981). In this study, a revised and enhanced version of Elefan I is used to estimated growth parameters $\mathrm{K}$ and $\mathrm{L}_{\infty}$.

Assumptions underlying this method are (Pauly \& David, 1981; Pauly, 1985): the von Bertalanffy's growth formula describes the average growth of the stocks under investigation, and growth pattern in the population is similar from year to year. Due to the second assumption, a wide number of growth curve may be applied on the same set of samples to result an optimum value of $K$ and $L_{\infty}$. It means that samples of some months could be considered as additional samples of the same months for the successive years. However, the algorithm of this method enabling the growth curve to follow the above scheme as the optimal criterium is matched, even for a single sample data set. In order to avoid an unreasonable number of growth lines being produced by this method, the sample sets used were defined from the beginning of the recruitment until the end of growth progression. The data sets were composed of regular samples having clear modal progression. By this way, growth lines would tend to pass the peaks of the same cohort as the maxima value of explained sum of peak also tend to follow modal progression.

Inaccurate estimate maybe resulted by a kind of seasonal oscillation of growth pattern that was possibly generated by biological or other phenomena. For this reason, the optional oscillation parameters integrated in the software were introduced during executing the program. Theoritical modification of von Bertalanffy equation used in the elefan was done by exerting an amplitude of seasonal oscillation factor and a point of which the growth line is oscillating, in the ordinary formula.

$L_{t}=L_{\infty}\left[1-e^{-K(t-t o)-(C \cdot K / 2 \pi) \cdot \sin \{2 \pi(t-t s)\}}\right]$

where:

$$
C=\text { amplitude of oscillation }
$$$$
\text { ts }=0.5+W P
$$

WP stands for winter point that is position of oscillating growth line. In case of $C=1$, the growth rate is zero when the winter point is reached once a year. For $\mathrm{C}=0$ the equation reverts to the original form of von Bertallanffy's growth formula.

\section{Reproduction}

\section{Maturity Scale}

The scale of maturity was adapted from several studies with differences species and ecological areas, because of inavailibilty of intensive investigation carried out in the Java Sea. Modification of the maturity criteria of Sardinella longiceps (Raja, 1967), Clupea harengus (Iles, 1984; Hempel, 1979), Sardinella aurita (Fontana, 1969) and manual of biological observation (Holden \& Raitt, 1974) were done.

Assumption underlying the determination of the maturity scales, for female fishes can be noted as follow:

a. The species are total spawner categories. It means that for which öocytes are ripe and immediately shed in a very short time.

b. The morphological changes of the ovaries are linearly related to the development of the ova.

The stage of maturity is reflected by the development of ova size; i.e. the size of ova that readily for spawning influence the relative size (in weight and volume) of the ovaries. So that, the size of ovaries can be used as indicator of the maturity stage.

The different maturity stages of the gonad used in this study are expressed as follow:

1. Stage 0: Undeterminable.

Gonad very small, usually white, and sex is not determinable by gross examination.

2. Stage I: Immature.

Ovaries: very small, shape oval elongated (carangids), slender (for non carangids species) color: white or transparent, ova not visible to naked eyes, but sex determinable by gross examination.

3. Stage II: Developed virgin.

It is included the Resting stage. Some clump of the eggs are visible to the naked eye, The shape of ovaries: elongated, length of ovary 2 to $3 \mathrm{~cm}$ for Decapterus spp. and occupy $1 / 3$ of body capacity.

4. Stage III: Early maturing or developing.

The ovaries are enlarged and occupy $2 / 3$ of body cavity, abdomen seems normal, ova are opaque.

5. Stage IV:Late maturing or mature.

The ovany ocoupies almost the whole body cavity, sometime the abdomen distended, ova are still opaque, but individual ova visible to the naked eyes. 
6. Stage V: Gravid/ripe.

Peritoneal cavity filled with ovaries, abdomen distended, some translucent eggs visible through the ovary wall and some of the translucent eggs are easily dislodged from the follicles or loose in lumen of ovary.

7. Stage VI: Spawning.

It would appear ready to spawn more ripe eggs and most of them are translucent and easily run out under slight pressure. Abdomen is distended.

8. Stage VII: Spent.

It includes recently spawned and post spawning fish and characterized by the presence of residual translucent eggs in various level of resorption. The ovaries are flaccid and occupy $2 / 3$ of body cavity. The size of these remnant of mature ova are about the same diameter as spawned ova.

In fact these criteria may result a bias generated by subjectivity as function of observations, more over these macroscopic observations were done by three persons in different landing place. In order to avoid this subjectivity, a common index figuring the percentage of gonads size is performed in this study. This index, denoted as gonado somatic index would be able to indicate a primary reproductive effort in fish and to reflect the development of the ova, i.e. stage of maturity. It is calculated as percentage of the gonads weight over body weight without gonads and stomach or with empty stomach, as expressed in the following formula (Miller, 1984):

$$
G S \mid=\frac{W_{a}}{\left(W_{b}-W_{g}\right)} \times 100
$$

where:

$W_{g}$ and $W_{b}=$ the gonads and body weight

In this case, exclusion of the digestive organ could be expected to improve the accuracy, but during the observation carried out in the field so far, almost all the specimens had empty stomach. However, the stomach content would not generate wide variation of the measurement, as the weight of empty stomach would be less than $2 \mathrm{~g}$. A microscopic verification of this index was conducted in order to confirm the relation of maturity staging by macroscopic examination with the development of ova size. It was focused on $S$. crumenophthalmus of which the determination was more difficult due to higher variation of the shape of ovaries.

\section{Average Size of the Mature Fish}

Statistically the length at first maturity would be the same measurement as the average length of the sexually matured fish that usually defined as the size where $50 \%$ of the fish to be mature from the distribution function like curve. If the length of the mature fish symmetrically distributed follows a normal like probability distribution density, the estimates of the length at first mature stage would be equal to the arithmetic mean. In this case, the use of mode or the mean would be efficient enough for estimating the parameter in question that formally defined as the probability of $50 \%$ of the distribution function.

The mature fish is defined as those of stage ripe and spawning conditions, which is indicated by a minimum value of gonado somatic index and particular condition of the ovaries. The gonado somatic index will be employed in a graphical presentation, instead of applying maturity stage criteria. A minimum value of each species is defined precisely as confirmed by microscopic examination. An arbitrary value will be used in order to give particular emphasis to certain case or simulation. In this case, specimens in spent or partly spent condition are excluded from the analysis since the value of gonado somatic index already decreases.

\section{RESULTS AND DISCUSSION}

\section{Size Progression}

This part is aimed to obtain a summary of the average of monthly pooled samples, and to describe modal progression of each species for validating the growth estimation. Figure $1 \mathrm{a}$ and $1 \mathrm{~b}$ show the trend of modal progression derived from mean length estimates of the polymodal frequency distribution samples. As can be seen in the figure, the average length of the cohort did not exhibit the same pattern at all of the years. However, monthly growth progression are not as smooth as exponential trend of the growth formula. Variation of length frequency distribution and the new recruits of $D$. russellii entering the Java Sea in period of 1991 to 1992 seem to be more variable than in other successive years.

In tracing growth progression, we ignore the length class strength, as far as the minor distribution can clearly represent any cohort. In many monthly pooled samples more than one length class can be dissected and determined but selection done only for the mean length values 
being able to indicate general trend of growth line. It is clear that most of the points belong to the major cohort (cohort that is clearly visible and gathers most of individuals). Thus, growth estimation can be performed using the data consist of a cohort clearly defined without selecting individual samples for tracing modal progression.

\section{Growth estimation}

\section{ELEFAN method}

Growth parameters are estimated by performing ELEFAN program and graphical methods of Gulland-Holt's and Ford-Walford's plots for some case and set of data. In general, estimation criteria or goodness of fit of ELEFAN depend on the Rn's values or ratio ESP/ASP. The highest values is considered as an indicator of the best estimate among several trials achieved during estimation.

First attempt to estimate growth parameters was done for $D$. russellii and $D$. macrosoma, applying it to period 1992 to 1995 data. Estimate parameters resulted by this step are averaged on the four cohorts i.e. cohort 1991, 1992, 1993, and 1994. In this case, the same pattern of growth curves pass all cohorts with origin on September (as assumed as date of birth) and ended by four or five lines passing unobserved length. Consequently, some modes and some cohorts were not hit or not properly passed by the growth lines. It could mean that each cohort has different pattern of growth line or the mean length of the distribution of samples for the same months are not always equal for different years. In this case, the main assumption underlying this method cannot be achieved perfectly and the accuracy of this method is reduced by this difference. In order to increase the precision of fitting, we divide the samples sets based on the period from the beginning of recruitment until the last month that a sample is still being passed by growth line. This procedure can give more reliable estimates as shown by the better position of growth lines that hit more precisely the mode of the major cohorts (Figure 2). All of the results of computation are listed in the Table 1.

However, 2 points can be outlined for intepretating the results. Firstly, strong oscillations exist somewhere under the period of sampling as indicated by flat lines drawn by the program and high values of amplitude of oscillation. Variation of growth pattern of all main species are clearly shown by different values of oscillation amplitude of each cohort. Some cohorts show a zero growth during certain periods (as indicated by the values of $\mathrm{C}$ being close or equal to unity).

The second point is a possible wide range of estimate values because of a presence of combination of $K$ and $L_{\infty}$ at the same Rn (Kleiber \& Pauly, 1991). So, applying this program with the maximum values of Rn's as a criterium would not directly give the best estimates. In practice, several trials and errors are obviously needed for defining the best one. Then, a pattern of maxima values of $\mathrm{Rn}$ at function of $\mathrm{K}$ for any sample set can be drawn by scanning values of $K$ at given fixed $L_{\infty}$ and other parameter estimates (as considered as the best estimate). The combination of $K$ and $L_{\infty}$ are derived from growth curve passing certain samples contributing the index of available sum of peak. This procedur is known as response surface that is available in the module of FiSAT system. An example of this procedur run for $D$. russellii of 1991 to 1993 is presented in Figure 3.

As stated by Shepherd et al. (1987) in Kleiber \& Pauly (1991) that an examination of the goodness of fit response an essential element in any assessment technique utilizing size composition data, since this surface will contain at least qualitative information on the confidence region of the parameter value and their degree of interdependence.

In this case, a combination of $\mathrm{K}$ and $\mathrm{L}_{\infty}$ are usually produced at each optimum value of $\mathrm{Rn}$, but different combination can result the same value of Rn's as demonstrated in the Table 2. Several trials have been attempted with the range of $K$ and $L_{\infty}$ covering the best estimate value being derived from ELEFAN. The results reveal that variability of combination of $L \infty$ and $K$ at high value of goodness of fit seem to be evident as vividly indicated by $D$. russellii of 1991 to 1992 period. Meanwhile, those of other periods do not behave similarly (not presented here), with lower scale of variability.

We notice that the curve patterns (the value of $\mathrm{Rn}$ as function of $\mathrm{K}$ at given $L_{\infty}$ ) reflects the characteristic of distribution structure of the data set generating the growth curve. We adopt this method to identify qualitatively, the growth pattern of the major cohort from different periods. The values of $R n$ are computed with $K$ variable at given fixed $L_{\infty}$ (the value $L_{\infty}$ is defined as the best estimate found from several runs) (Figure 3). As shown in this figure, different patterns are exhibited by certain periods, particularly, by major cohort of 1991 or 1992 (except for S. gibbosa). 


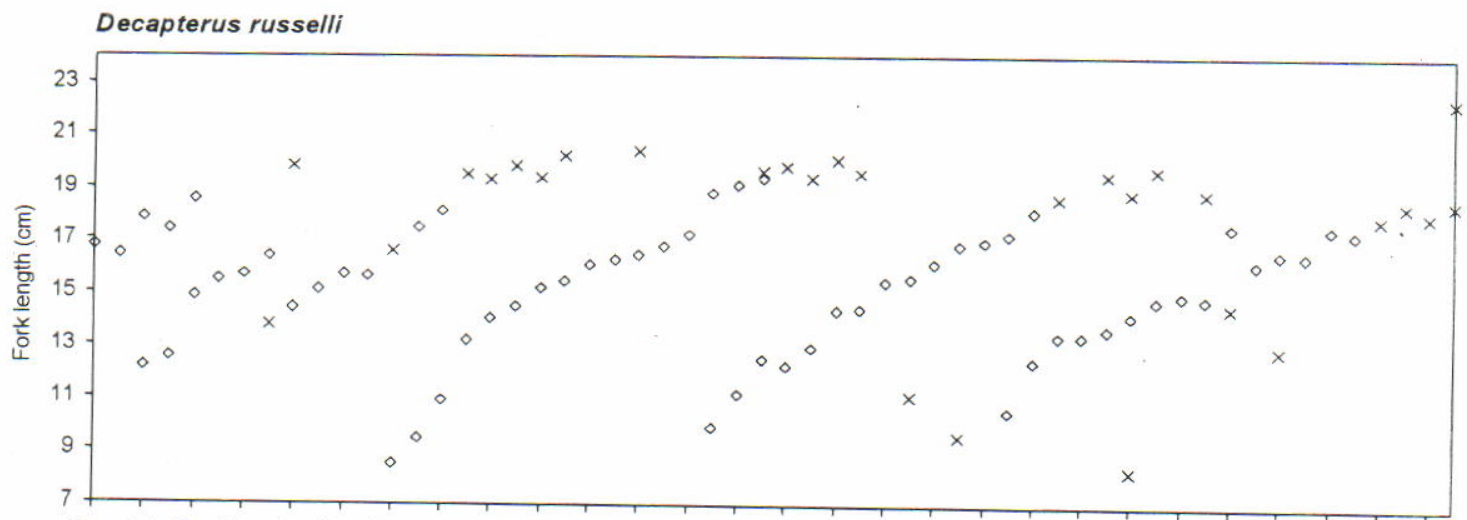

May Jul Sep Nov Jan Mar May Jul Sep Nov Jan Mar May Jul Sep Nov Jan Mar May Jul Sep Nov Jan Mar May Jul Sep Nov Months (1991-95)
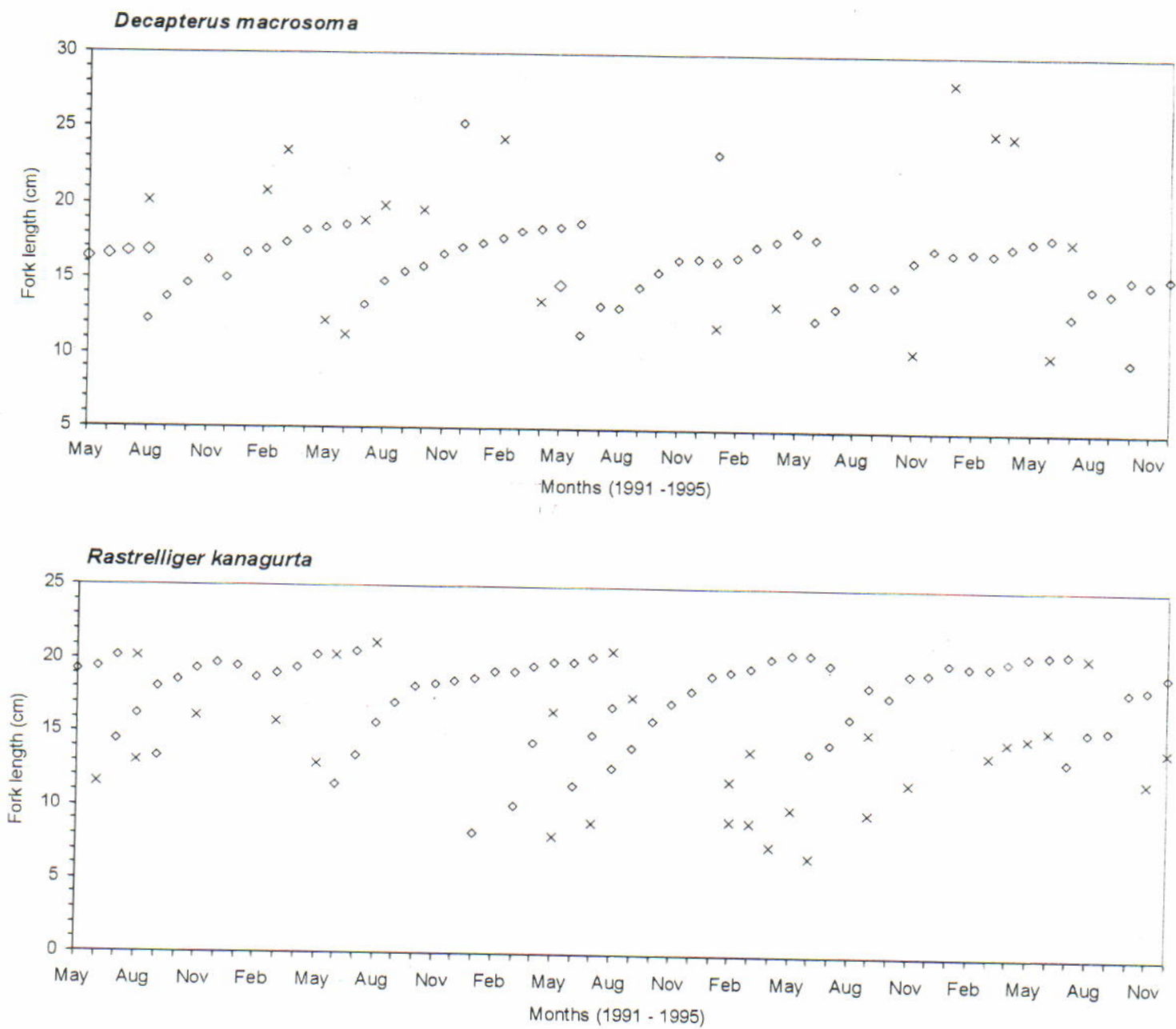

Figure 1a. Monthly mean length derived from length frequency data.

Remarks: $x$ 's = calculated from minor distribution otherwise from major modal

\section{Other Method}

Other methods of estimation using growth increment of unequal interval of months or using successive length at equal interval are performed for the best data available in this study (i.e. D. russellii samples). The graphical plot of growth increment at its corresponding midlength of Gulland-Holt's Plot or plot of length of successive periods of Ford-Walford Plot result unreasonable estimates (Table 3). 

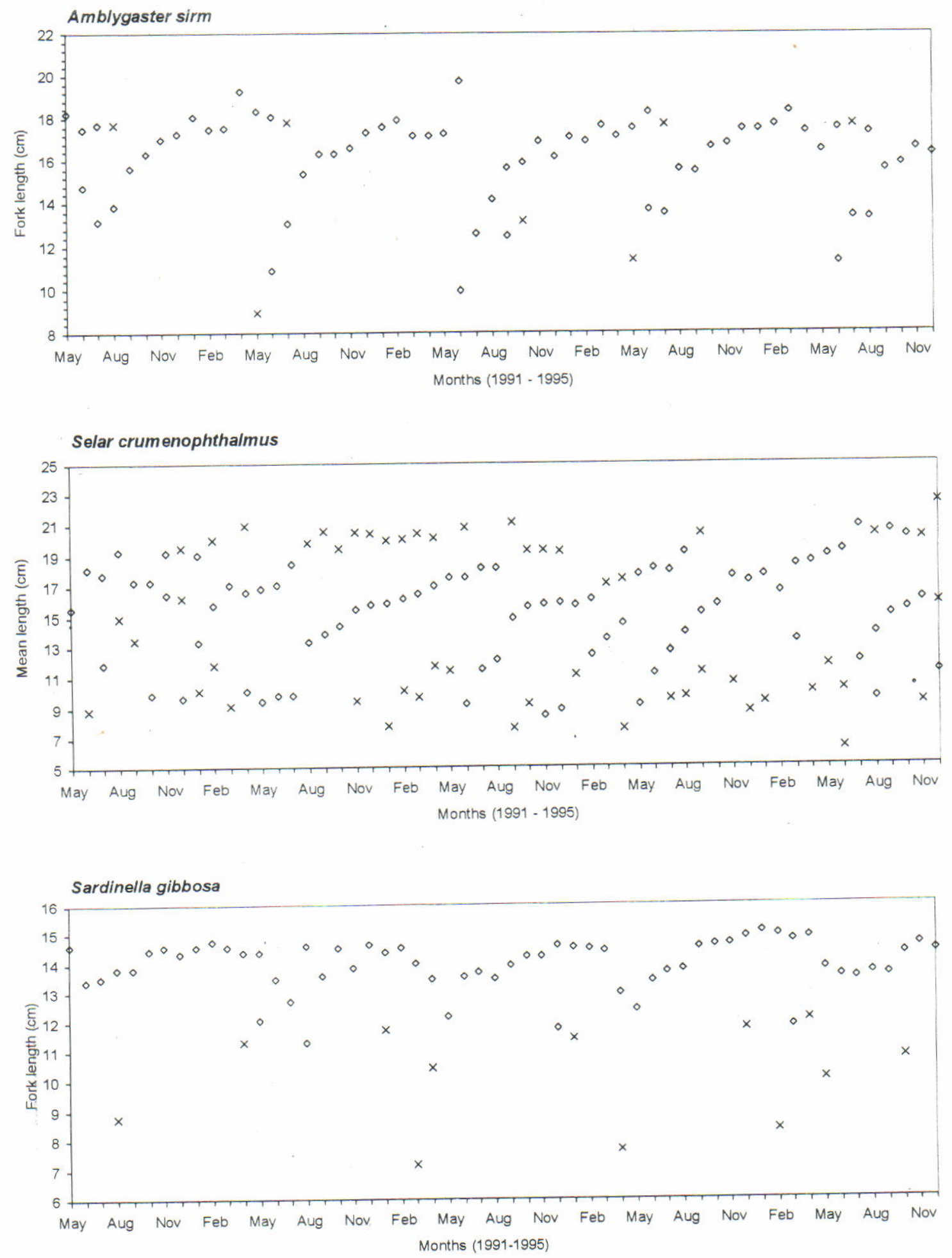

Figure 1b. Monthly mean length derived from length frequency data.

Remarks: $x$ 's = calculated from minor distribution otherwise from major modal

The estimates values of $L_{\infty}$ tend to be too low compared with the maximum length observed $(27.5 \mathrm{~cm})$. However, there is no strong mode of the large size (close to maximum length), used in the calculations (excluding few data of observations on the large class). Therefore, it tends to result relatively lower value of $L_{\infty}$ estimates that statistically may be correct (as derived from regression). If the largest class is included in computation, the $L_{\infty}$ estimate value normally 

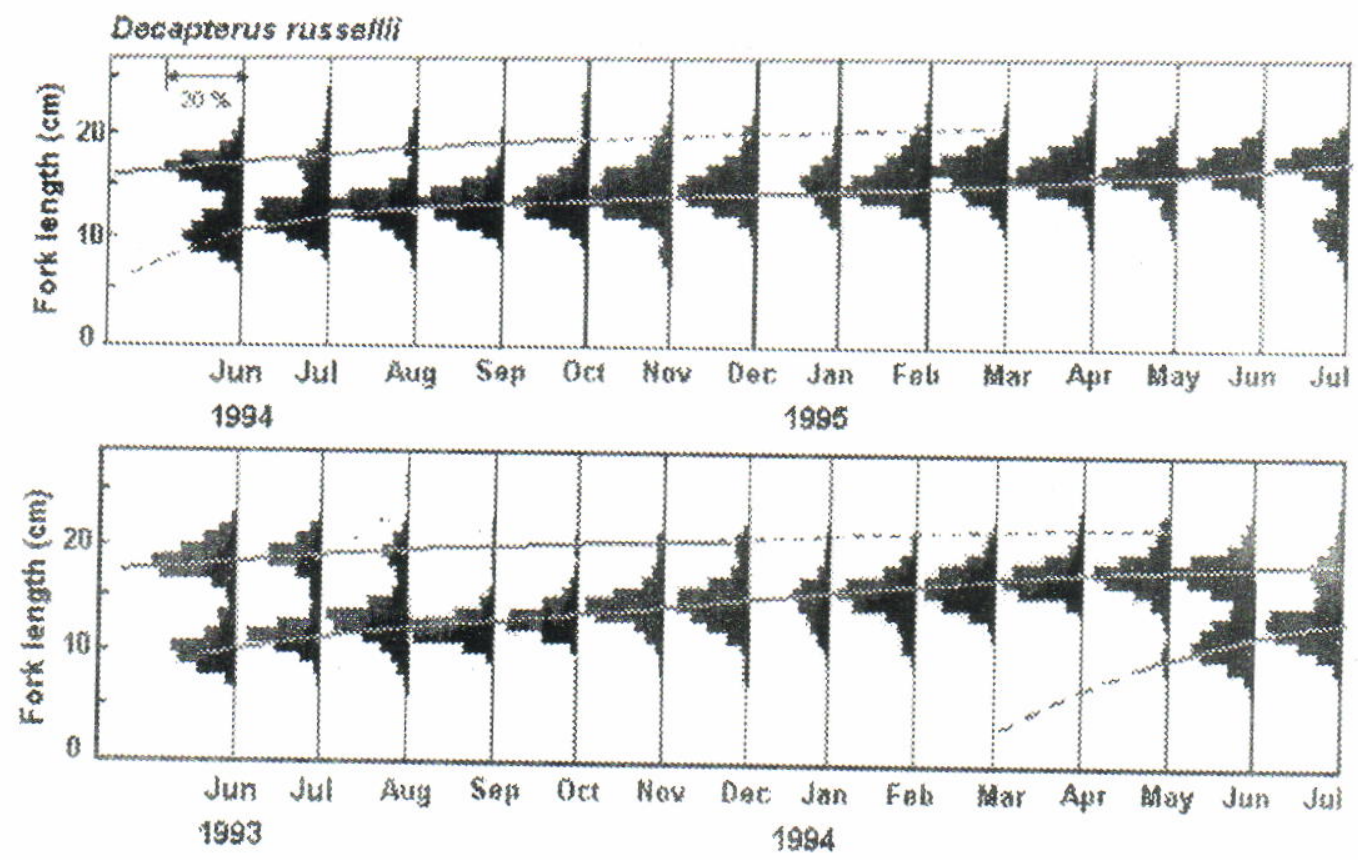

Decaporas macros anse
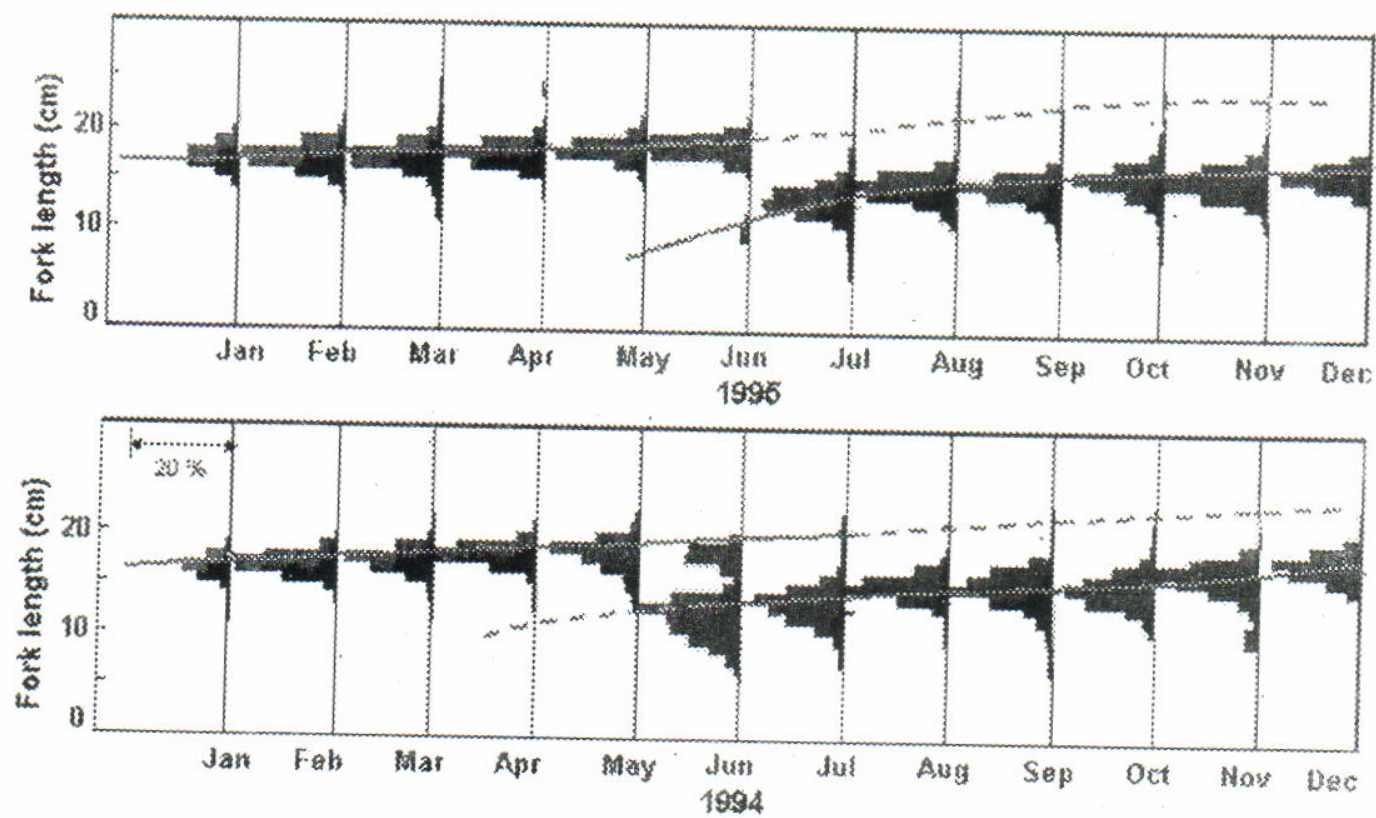

Figure 2. Growth progression of $D$. russellii and D. macrosoma traced by performing Elefan routine.

greater than the observed maximum length that can be empirically approximated as $L_{\infty} \sim$ Length maximum/0.95 (Matthews, 1990).

The different estimates resulted by those methods can be explained in two points:

1. The ELEFAN has an ability in tracing the oscillated growth progression, while the last methods are derived from non oscillated growth curve.
2. In relation to the procedure in defining the mean of length distribution. In ELEFAN, the mean of the distribution is defined as a mid of length class corresponding to the highest index. This index reflect the strength of probability of the class length, and the modal length is indicated by the highest value. It is derived by standardizing the moving average of the observed frequency (Pauly \& David, 1981). We can compare the mean estimates computed 


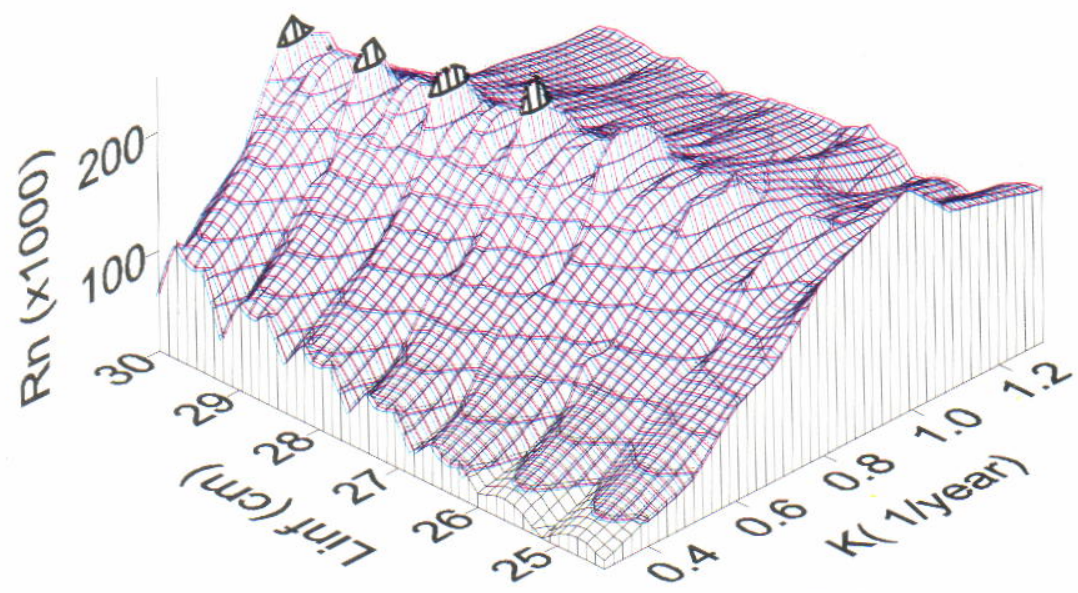

Figure 3. An example of possibles combination of growth parameters ( $K$ and $\left.L_{\infty}\right)$ of $D$. russellii from 1992 to 1993 data.

Remarks: the bold line of the peaks are optimal combination with the same values of $\mathrm{Rn}$

Table 1. Estimate values of growth parameters computed using ELEFAN

Remarks: $\mathrm{Ss}=$ starting sample; $\mathrm{SI}=$ starting length

\begin{tabular}{|c|c|c|c|c|c|c|c|}
\hline Species & $\begin{array}{c}\mathrm{L}_{\infty} \\
\text { Cohorts }\end{array}$ & $\begin{array}{c}\mathrm{K} \\
(\mathrm{cm})\end{array}$ & $\begin{array}{c}\text { C } \\
\left(\text { year }^{-1}\right)\end{array}$ & $W p$ & Ss & SI & $\mathrm{Rn}$ \\
\hline \multicolumn{8}{|c|}{ Decapterus russellii } \\
\hline 1991-1992 & $28.00-29.00$ & $0.85-0.95$ & 0.3 & 0.3 & 1 & 18.0 & 0.265 \\
\hline $1992-1993$ & $27.25-27.6$ & $0.73-0.75$ & 0.6 & 1.0 & 7 & 15.5 & 0.247 \\
\hline 1993-1994 & 29.25 & 0.53 & 0.3 & 0.1 & 1 & 10.0 & 0.225 \\
\hline 1994-1995 & 28.50 & 0.51 & 0.7 & 0.9 & 1 & 9.0 & 0.218 \\
\hline 1992-1995 & 29.00 & 0.60 & 0.9 & 0.9 & 3 & 15.0 & 0.187 \\
\hline \multicolumn{8}{|c|}{ Decapterus macrosoma } \\
\hline $1991-1992$ & $29.25-30.0$ & $0.7-0.75$ & 0.5 & 0.3 & 5 & 16.5 & 0.515 \\
\hline $1992-1993$ & 29.25 & 0.59 & 0.6 & 0.1 & 2 & 13.0 & 0.409 \\
\hline 1993-1994 & 29.5 & 0.75 & 1.0 & 0 & 10 & 17.0 & 0.455 \\
\hline 1994-1995 & 30.25 & 0.875 & 0.9 & 0.1 & 5 & 14.0 & 0.320 \\
\hline 1992-1995 & 30.45 & 0.6 & 0.5 & 0.1 & 7 & 12.0 & 0.339 \\
\hline \multicolumn{8}{|c|}{ Rastrelliger kanagurta } \\
\hline \multirow[t]{2}{*}{ 1991-1992 } & $29.5-30.0$ & $0.8-0.85$ & 0.9 & 0.1 & 6 & 19.5 & 0.250 \\
\hline & 29.25 & 0.975 & 0.6 & 0.1 & 3 & 16.0 & 0.256 \\
\hline $1992-1993$ & 30.0 & 0.71 & 1.0 & 0 & 10 & 21.0 & 0.255 \\
\hline 1993-1994 & 29.5 & 0.825 & 0.7 & 0.3 & 2 & 20.5 & 0.258 \\
\hline 1994-1995 & 30.0 & 0.7 & 1.0 & 0.1 & 8 & 8.0 & 0.279 \\
\hline \multicolumn{8}{|c|}{ Amblygaster sirm } \\
\hline 1991-1992 & $25.5-26.0$ & $1.0-1.1$ & $0.6-1.0$ & 0.1 & 1 & 13.0 & 0.480 \\
\hline $1992-1993$ & 26.0 & 0.825 & 1.0 & 0.1 & 2 & 10.5 & 0.500 \\
\hline \multirow[t]{2}{*}{ 1993-1994 } & 26.25 & 0.65 & 0.5 & 0 & 13 & 13.0 & 0.435 \\
\hline & 25.5 & 0.8 & 0.9 & 0.1 & 2 & 12.5 & 0.357 \\
\hline 1994-1995 & 25.25 & 0.65 & 0.8 & 0 & 4 & 15.0 & 0.340 \\
\hline \multicolumn{8}{|c|}{ Selar crumenophthalmus } \\
\hline \multirow[t]{2}{*}{$1991-1992$} & 28.5 & 0.9 & 0.9 & 0.5 & 4 & 18.0 & 0.210 \\
\hline & 28.5 & 1.2 & 1.0 & 0.9 & 2 & 11.5 & 0.204 \\
\hline $1992-1993$ & 26.5 & 0.8 & 0.9 & 0 & 11 & 16.0 & 0.233 \\
\hline \multirow[t]{2}{*}{$1993-1994$} & 27.75 & 1.1 & 0.1 & 0.5 & 1 & 17.0 & 0.185 \\
\hline & 28.0 & 0.8 & 0.4 & 0 & 11 & 9.5 & 0.163 \\
\hline 1994-1995 & 29.0 & 0.975 & 0.3 & 0.9 & 3 & 0.5 & 0.180 \\
\hline \multicolumn{8}{|c|}{ Sardinella gibbosa } \\
\hline $1993-1994$ & 24.0 & 0.64 & 1.0 & 0.9 & 5 & 13.0 & 0.410 \\
\hline $1994-1995$ & 24.25 & 0.53 & 0.1 & 0.9 & 6 & 14.0 & 0.538 \\
\hline
\end{tabular}


Table 2. An example of response surface applied to D. russellii data

Remarks: elements are the Rn's values. Shadowed are plateau on high values of $\mathrm{Rn}$, bold figures are the maxima

\begin{tabular}{|c|c|c|c|c|c|c|c|c|c|c|c|}
\hline \multirow{2}{*}{\multicolumn{12}{|c|}{ Period of sampling: 1991-1992 }} \\
\hline & & & & & & & & & & & \\
\hline $\mathrm{K}\left(\right.$ year $\left.^{-1}\right)$ & 27.0 & 27.3 & 27.6 & 27.9 & 28.2 & 28.5 & 28.8 & 29.1 & 29.4 & 29.7 & 30.0 \\
\hline 1.000 & 0.196 & 0.238 & 0.220 & 0.217 & 0.180 & 0.180 & 0.169 & 0.196 & 0.196 & 0.180 & 0.172 \\
\hline 0.975 & 0.195 & 0.215 & 0.238 & 0.220 & 0.220 & 0.180 & 0.180 & 0.169 & 0.178 & 0.196 & 0.180 \\
\hline 0.950 & 0.201 & 0.178 & 0.215 & 0.265 & 0.220 & 0.214 & 0.197 & 0.180 & 0.169 & 0.185 & 0.196 \\
\hline 0.925 & 0.194 & 0.201 & 0.193 & 0.215 & 0.265 & 0.220 & 0.212 & 0.197 & 0.180 & 0.169 & 0.185 \\
\hline 0.900 & 0.187 & 0.186 & 0.183 & 0.199 & 0.226 & 0.265 & 0.220 & 0.212 & 0.209 & 0.180 & 0.185 \\
\hline 0.875 & 0.162 & 0.189 & 0.186 & 0.183 & 0.199 & 0.215 & 0.265 & 0.265 & 0.212 & 0.212 & 0.180 \\
\hline 0.850 & 0.166 & 0.162 & 0.183 & 0.186 & 0.200 & 0.209 & 0.215 & 0.265 & 0.263 & 0.212 & 0.212 \\
\hline 0.825 & 0.122 & 0.149 & 0.164 & 0.182 & 0.183 & 0.185 & 0.209 & 0.215 & 0.237 & 0.255 & 0.212 \\
\hline 0.800 & 0.123 & 0.127 & 0.155 & 0.164 & 0.169 & 0.178 & 0.185 & 0.209 & 0.221 & 0.237 & 0.255 \\
\hline 0.775 & 0.109 & 0.122 & 0.139 & 0.137 & 0.156 & 0.169 & 0.195 & 0.184 & 0.193 & 0.221 & 0.215 \\
\hline 0.750 & 0.103 & 0.114 & 0.122 & 0.139 & 0.136 & 0.139 & 0.1 & 0.176 & 0.205 & 0.193 & 0.221 \\
\hline \multicolumn{12}{|c|}{ Period of sampling: $1992-1993$} \\
\hline $\mathrm{K}\left(\right.$ year $\left.^{-1}\right)$ & 28.0 & 28.2 & 28.4 & 28.6 & 28.8 & 29.0 & 29.2 & 29.4 & 29.6 & 29.8 & 30.0 \\
\hline 0.800 & 0.191 & 0.173 & 0.169 & 0.172 & 0.174 & 0.171 & 0.172 & 0.172 & 0.176 & 0.174 & 0.175 \\
\hline 0.770 & 0.213 & 0.199 & 0.199 & 0.196 & 0.189 & 0.172 & 0.174 & 0.171 & 0.172 & 0.172 & 0.176 \\
\hline 0.740 & 0.215 & 0.205 & 0.213 & 0.199 & 0.199 & 0.196 & 0.204 & 0.192 & 0.171 & 0.176 & 0.184 \\
\hline 0.710 & 0.235 & 0.231 & 0.229 & 0.224 & 0.209 & 0.199 & 0.197 & 0.205 & 0.204 & 0.199 & 0.192 \\
\hline 0.680 & 0.236 & 0.237 & 0.235 & 0.240 & 0.233 & 0.238 & 0.233 & 0.199 & 0.205 & 0.215 & 0.213 \\
\hline 0.650 & 0.198 & 0.237 & 0.236 & 0.245 & 0.235 & 0.240 & 0.237 & 0.253 & 0.233 & 0.222 & 0.207 \\
\hline 0.620 & 0.174 & 0.171 & 0.195 & 0.220 & 0.226 & 0.245 & 0.235 & 0.244 & 0.237 & 0.242 & 0.242 \\
\hline 0.590 & 57 & 0.157 & 0.178 & 0.171 & 0.189 & 0.190 & 0.196 & 0.228 & 0.234 & 0.240 & 0.244 \\
\hline 0.560 & 0.143 & 0.142 & 0.157 & 0.157 & 0.163 & 0.160 & 0.189 & 0.189 & 0.190 & 0.198 & 0.203 \\
\hline 30 & 0.122 & 0.129 & 0.143 & 0.140 & 0.147 & 0.145 & 0.162 & 0.1 & 0.171 & 0.171 & 0.189 \\
\hline 0.500 & 0.120 & 0.117 & 0.118 & 0.12 & 0137 & 0147 & 0.147 & 0.14 & 0.151 & 0.151 & 0.151 \\
\hline \multicolumn{12}{|c|}{ Period of sampling: $1993-1994$} \\
\hline $\mathrm{K}\left(\right.$ year $\left.^{-1}\right)$ & 28.0 & 28.3 & 28.6 & 2 & 29 & 29 & 29 & 30 & 30 & & 31.0 \\
\hline & 0.100 & 0.113 & 118 & 0.117 & 0.1 & 0.120 & 0.1 & 0.114 & 0.110 & 0.118 & 0.124 \\
\hline 80 & 02 & 0.100 & 0.099 & 0.100 & 0.120 & 0.118 & 0.123 & 0.121 & 0.114 & 0.110 & 0.107 \\
\hline & 09 & CE & 0 & 0.105 & 0.101 & 0.099 & 0.120 & 0.120 & 0.124 & 0.119 & 0.121 \\
\hline & 23 & 16 & 0.110 & 0.112 & 0.113 & 0.106 & 0.100 & 0.098 & 0.101 & 0.121 & 0.120 \\
\hline & 0 & 04 & 15 & 0.123 & 0.130 & 0.126 & 0.1 & 0.117 & 0.114 & 0.103 & 0.102 \\
\hline & & & & 0.114 & 0.121 & 0.118 & 0.1 & 01 & 0.133 & 0.137 & 0.130 \\
\hline & 0 & & 64 & 5 & 8 & 0.131 & 0.117 & 0.123 & 0.139 & 0.129 & 0.128 \\
\hline & ar: & 6 & 0.176 & 79 & 7. & 0.225 & 0.1 & 0.151 & 0.147 & 0.133 & 0.127 \\
\hline & & & & -5 & & 0.160 & 0.1 & 0.1 & 0.183 & 0.194 & 0.191 \\
\hline 0.400 & 0.079 & 0.069 & 0.066 & 1 & 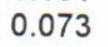 & 0.087 & 0.106 & 0.125 & 0.139 & 0.140 & 0.138 \\
\hline \multicolumn{12}{|c|}{ Period of sampling: 1994-1995 } \\
\hline $\mathrm{K}\left(\right.$ year $\left.^{-1}\right)$ & 27.75 & 27.88 & 28.00 & & & & 28.50 & 28. & 28.75 & 28.88 & 29.00 \\
\hline & & & & & & & 0.131 & 0.135 & 0.131 & 0.123 & 0.129 \\
\hline 0 & & 43 & 0.138 & 0 & & 0.122 & 0.141 & 0.139 & 0.139 & 0.134 & 0.142 \\
\hline & & & & & 0.148 & 0.1 & 01 & 0.118 & 0.125 & 0.144 & 0.142 \\
\hline & 0.176 & & & & & 0.153 & 0.155 & 0.157 & 0.153 & 0.148 & 0.136 \\
\hline & 200 & & 0.187 & 0.182 & 0.176 & 0168 & 0.172 & 0.168 & 0.169 & 0.165 & 0.154 \\
\hline & & & & & & 0.193 & 0.193 & & 0.180 & 0.168 & 0.176 \\
\hline & 21 & 0.124 & 0.146 & & & 0.182 & & & 0.208 & 0.199 & 0.193 \\
\hline 0. & & & 0.104 & 0.113 & 0.122 & 0.123 & & 132 & 0.146 & 0.169 & 0.199 \\
\hline & & & & & & 0.1 & & & $0: 120$ & 0.122 & 0.125 \\
\hline & & & & & 0.0 & & & & 0.078 & 0.081 & 0.094 \\
\hline 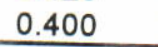 & 0.096 & 0.091 & 0.088 & .089 & 0.087 & 0.095 & 0.09 & 0.086 & 0.089 & 0.09 & 0.084 \\
\hline
\end{tabular}

using Batacharya and Normsep methods with approximate value derived by this method. For the major distribution (clear distribution), the difference of mean length estimates seem to be random and low (less than one $\mathrm{cm}$ ), but, notable differences are observed for minor distributions. 
In general, the algorithm of this progam tends to drawn repeatly the growth curve and to hit the large groups of fish. Consequently, the $L_{\infty}$ will be close to the maximum size group. In the $\mathrm{G}-\mathrm{H}$ methods we ignore this group as its mean length is not clear. It is reason why the estimate $L_{\infty}$ derived from the ELEFAN are higher than that of G-H method.

Table 3. Te results of growth parameter estmates of $D$. russellii by applying graphical methods

\begin{tabular}{cccccc}
\hline Periods & $\begin{array}{c}\mathrm{K} \\
\text { (/year) }\end{array}$ & $\begin{array}{c}\mathbf{L}_{\infty} \\
(\mathbf{c m})\end{array}$ & $\begin{array}{c}\text { Range of mean } \\
\text { length used in } \\
\text { regressions }\end{array}$ & No. Points & Methods \\
\hline Dec 91-Dec 92 & 1.21 & 24.08 & $13.78-20.20$ & 8 & G-H Plot \\
& 0.90 & 24.49 & $13.78-20.20$ & 12 & F-W Plot \\
May 92-Aug 93 & 1.48 & 21.05 & $8.5-19.38$ & 15 & G-H Plot \\
& 1.29 & 21.32 & $9.5-19.26$ & 10 & F-W Plot \\
Jun 93-Jul 94 & 1.27 & 20.56 & $9.93-18.09$ & 13 & G-H Plot \\
& 1.47 & 21.01 & $10.55-17.21$ & 8 & F-W Plot* \\
\hline
\end{tabular}

Remarks: -H Plot:Gulland-holt Plot; $-W:$ Ford-Walford Plot; * regression $=0.36$, the others more than 0.85

1. Decapterus russellii

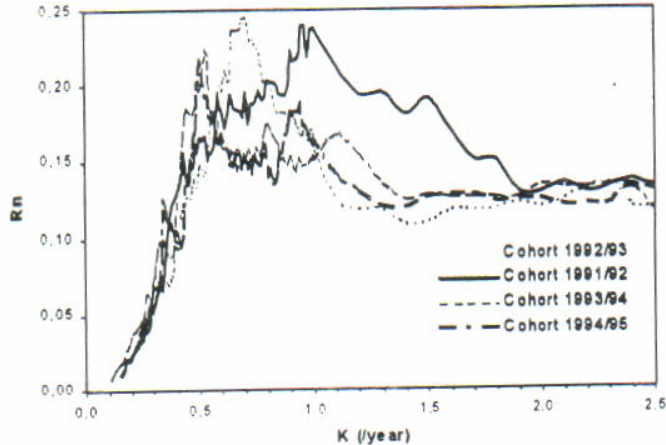

3. R. kanagurta

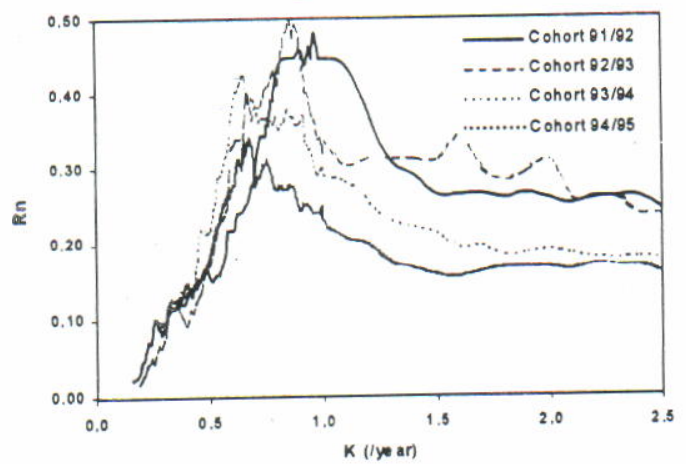

5. S. crumenophthalmus

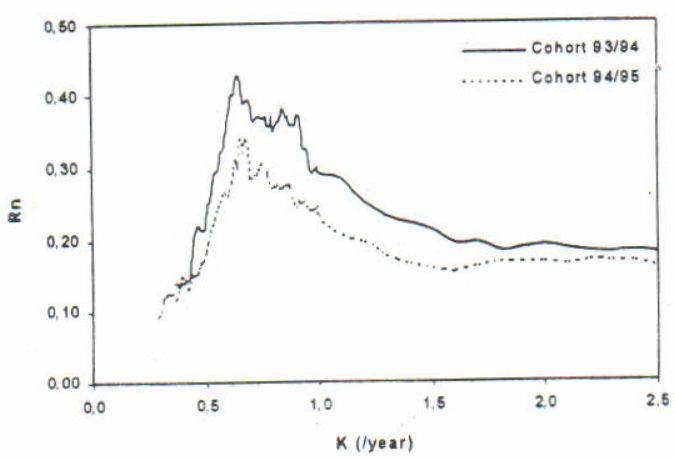

2. D. macrosoma

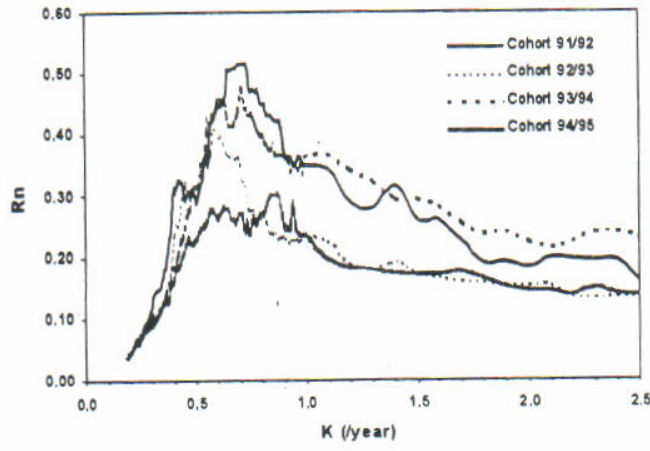

4. A. sirm

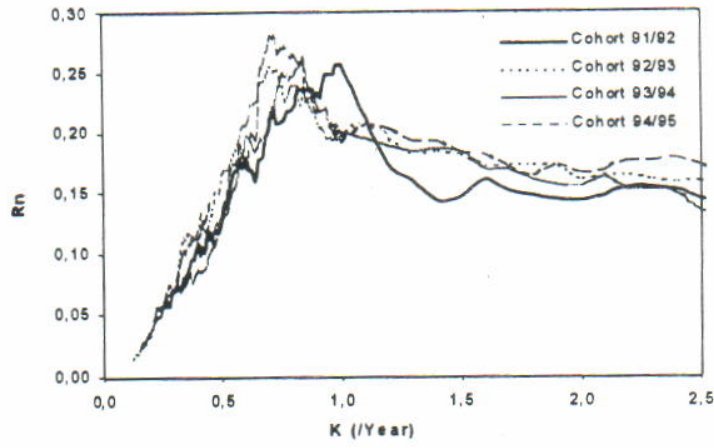

6. S. gibbosa

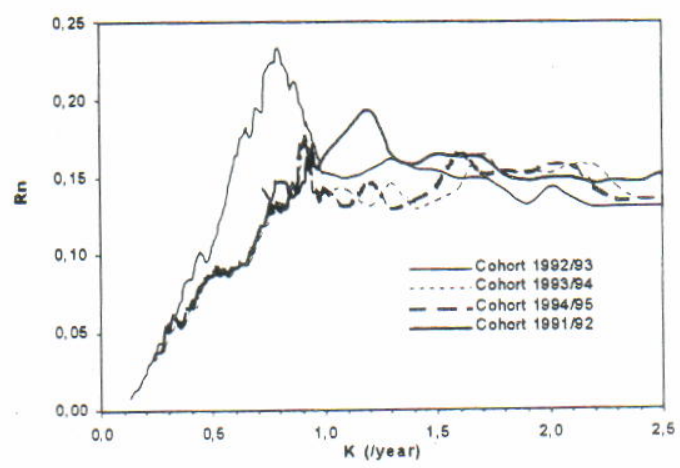

Figure 4. Scanning values of $\mathrm{K}$ at given $\mathrm{L}_{\infty}$ and other parameter estimates. 


\section{Comparison of Estimates}

A comparison of these results with those from other regions or populations reveal that high variation of growth parameters estimate is apparent. The most reasonable seems then to compare with that of the same population (the Java Sea population) and other populations of neighboring regions.

Several previous studies of the growth estimations were performed using the same methods length measurements as applied in this study, i.e. in the years 1982 to 1983 (Sadhotomo \& Atmaja, 1985), 1985 to 1986 (Atmaja, 1988), and 1991 to 1993 (Suwarso et al., 1995). A reestimate of growth parameters was also done using first version of ELEFAN I (Dwiponggo et al., 1986). Comparison growth parameterts of the same area (population) would be more valid because of the same fishing method used by the sample boats (purse seiners). In this case we cannot compare the level of accuracy of the estimates, although the goodness of fit for this purpose is available as denoted as Rn. More samples or periods of observation in the data set usually result in lower value of $\mathrm{Rn}$, because more samples are not passed by the growth line.

In general, the estimate value of $\mathrm{K}$ in this study are higher and the $L_{\infty}$ are lower than those of the Philippines waters, but not so much different with the result of the same population. Before comparing these estimates with those of other studies, it is necessary to standardize our measurement using TL-FL relationship ${ }^{1}$. Once this done, we can see that our estimates of $K$ and $L_{\infty}$ tend to lie in the range of the values of other studies in the same area. But different setting of input data used by other studies (Ingle and Pauly, 1984; Dwiponggo et al., 1986; Widodo, 1988) could make their growth estimates become incomparable. Two reasons can be pointed out. Firstly, the data sets used by other studies were not based on appropriate periods but likely based on calendrical period (from January to the last month) or non predefined periods (from any month to the last period of sampling). Secondly, several estimations were based on short periods of sampling as indicated by some sets of data used in those studies consisted of less than one year of observations (as used in Dwiponggo et al., 1986).

\footnotetext{
1 For D. russellii: $T L=-0.481+1.137 \mathrm{FL}\left(r^{2}=0.987, n=1171\right.$,

$t_{(1169)}=216.1, S_{(F L)}=0.005$ ) For $D$. macrosoma: $T L=-0.194+0.166$ $F L\left(r^{2}=0.85, n=120\right)$ (Widodo, 1988)
}

The following paragraphs are focused on annual and interannual variability of parameter estimates with emphazing on the following points a) characteristictic of $K$ pattern; b) the growth and oscillation patterns and their relation to migration; and c) a probable ecological impact on the structure of length composition data.

\section{K's Pattern}

Apparently, a single estimation of growth parametters is rarely obtained from analysis of length composition data set. It is more likely that a range of $K$ and $L_{\infty}$ is produced over a plateau on the goodness of fit criteria response surface (Shepherd, 1987). In the ELEFAN method, a combination of $K$ and $L_{\propto}$ is usually produced at each optimum value of $\mathrm{Rn}$, but different combination can result the same value of Rn's. We notice that the pattern of $\mathrm{K}$ at given $\mathrm{L}_{x}$ intrinsically characterizes the length composition data or is considered as an indicator of characteristics of the length data set.

However, it is beyond the scope of this study to evaluate in details the relationship between the type of the data set and the growth pattern. In most general reason of such phenomenon is that if the kurtosis of the distribution is considerably high or if several modes exist in a sample, there is a possibility for more than one growth lines to be drawn passing that sample. Empirically, a flat histogram tends to be a polymodal frequency distribution (Harding, 1949; Batacharya, 1967) and restructurization of sample performed by ELEFAN usually results in more than one class length (Pauly \& David, 1981).

Usually, the purpose of this scanning and evaluation on the table of response surface (e.g. Table 2) is to find the best estimate of $K$ at given value of $L_{\infty}$, but in this study we use this way for evaluating the characteristic of $\mathrm{K}$ pattern as derived from different length composition data. Comparing the $\mathrm{K}$ pattern of different years or cohorts reveals that the data set 1991 to 1992 exhibit in different pattern (Figure 4). A wider range of $K$ seems to be generated by polymodal distribution of larger size of fish at the first half year and the existing of more that one major cohorts during that period. It means that a steeper growth line can be drawn passing higher value of length without reducing the value of $\mathrm{Rn}$ significantly.

Theoretically, there are some possible factors influencing the interannual variability of growth rate 
of pelagic fishes in the Java Sea. The first one is related to the stock abundance. In this case, density dependence of growth rate corresponds to an ecological adaptation for maintaining high abundance, for instance by extending their feeding ground. The second factor is an interannual change in avaibility of food within the limit of adaptability of the species. These phenomena have been proved for japanese sardine (Sardinops melanostictus) by evaluating the long term data of abundance and growth parameters estimate (Wada \& Kashiwai, 1991).

However, our data show an inverse phenomena. In 1991 the abundance was relatively higher than in other periods as indicated by dramatic increase of catch per day of fishing and total landing (Potier \& Sadhotomo, 1995; Potier, 1998; Sadhotomo \& Widodo, 1994). In relation to exploitation aspect, an expansion of fishing ground will clearly add the data of other subareas that may consist of a new length class to the samples, but the more recent data have less length class than that of 1991 to 1992 (eventhough the historical change of fishing strategy indicated that recent fishing ground usually more extensive). So, for the periods of 1991 to 1995 , the impact of fishing pattern on variability of length class in the data set can be ignored.

The most probable factor is the change in migration pattern of migrant species in the Java Sea during the year 1991. However, this may be related to interannual changes of hydrographical pattern inside the Java Sea. Specially, an impact of El Niño can result in a longer duration of oceanic water penetration in the Java Sea and a decrease of desalination process (Sadhotomo \& Durand, 1997). During this period the migrant species from inside the Java sea (that grew up in this area) can mix with new immigrant from other areas, i.e from the northern and eastern archipelagos and stay longer than in a normal year. Then these mixed populations would have entered the fishery with different length structure.

\section{Seasonal Growth Oscilations}

Almost all the growth patterns obtained through ELEFAN in this study display strong oscillation during certain period (as function of WP) during which the individual growth decreases in an amplitude value (C). The values of amplitude are considerably high, estimated to be in the range between 0.1 to 1 (Table 1). Following the discussion on the topic related to seasonal growth (Pauly, 1990; Soriano \& Pauly, 1989; Sparre, 1991), we know that the growth of fish performs seasonal oscilation. Empirically, temperature differences between winter and summer as small as $2^{\circ} \mathrm{C}$ (as observed in tropical area) are sufficient to induce detectable seasonal growth oscilation (Pauly \& David, 1981).

Evaluation on this aspect would be essential as far as one concerns on the use of length based model in stock assessment. Most of the classic model such as dynamics pooled model of Beverton \& Holt (1957) are based on non seasonal growth pattern. However, bias can be generated in computing age conversion from length using non seasonal parameter estimates. Some solution have been proposed, by modifying the basic models such as for length converted catch curve (Pauly, 1990) and for yield per recruit (Sparre, 1991).

Such growth oscilations which are detected in our data set may be governed by two possible causes a) biological and ecological phenomena, i.e. intrinsic characteristic of the species having their growth oscilating. seasonally and migration; and $b$ ) an artifact of the structure of length data set that caused by non bioecological reasons, such as heavy pressure of fishing on certain class sizes.

These causes correspond to other factors that can be hypothesized as the source of influence on seasonal growth oscilation:

a. The first is the salinity or other hydrographic parameter differences of the opposite seasons. We observed that the difference of maximum and minimum salinity in the middle of the Java Sea (around Karimunjawa Island) is considerably high (about $3 \%$ ), as well as the differences of transparancy. In this case we ignore the influence of temperature suggested by many authors, due to non significantly differences of temperature during the Northwest and Southeast monsoon.

b. The second factor is in relation to competition and predation during their stay in the Java Sea. Competition can be defined as a population process (not at level of single organism) though many of its result are manifestated as effect on organism of which population are composed. High competition can be hyphothesized to be occured in the Java Sea with an impact on decreasing of the individual growth, during the period of Southeast monsoon when the abundance of pelagic fishes tremendously increase.

Analogous the removal by fishery to that by predation might be applicable. It could exert influence upon individual growth on the 
common size caught by purse seine (i.e. in the range of $\pm 12-18 \mathrm{~cm}$ in $\mathrm{FL}$ for five main species, and $\pm 10-14 \mathrm{~cm}$ for $S$. gibbosa). The oscillations (marked by 'flatter growth curves') mostly occur in the same size range as the dominant size contributing to the purse seine catch. But, we notice that the high removal of these size is clearly owing to the high abundance of fish, is not caused by selectivity of the fishing gear.

c. The third factor is migration effect on the growth increment of some range of length that finally produce a pseudo length classes and individual growth, as well. So far, an indications of the emigration from the Java Sẹ have been well described (Hardenberg, 1938; Sadhotomo \& Potier, 1995).

The first factor is impossible to solve and no reference for these species are found, while for the second one, an emergent effect of this competition would not be indicated by an immediate adaptation i.e. by reducing invidual growth. Meanwhile deleterious impact of the catch removal on this size does not exist as indicated by dominant contribution to catch of purse seine for all years. If there is a high removal of some length classes being due to fishing, the length structure would not be immediately reflected in the samples collected from the purse seine catches. If this is the case, dramatic annual fluctuation of length structure of the catch will exist, due to fluctuation of numbers of progeny. It is clear that different length classes are present at different densities as being reflected by composition or structure of length of the samples (within the assumption that the catches represent the abundance at sea). In this case, there is no reasonable information for explaining a sudden effect on individual growth. Moreover, in case of disappearence of large fish, the effect of competion is impossible to cause an extinction of a class length (a modal distribution) of species. Another factor may influence the variability of length of older classes. Hence, 2 possibilities of difference interpretations on the individual growth for the old classes. a) as fish become older, individual growth differences create higher range variability of length within the same cohort of the older age (Casselman, 1987); and b) but, on the contrary, if most of individual fishes uniformly grow up, the length of the older ones would not vary, for instance, the difference in length. of 3 and 15 month old may be greater than that between one and 2 years old fishes. Naturally, there 2 possibilities are not capable to change the length structure that finally produce low growth of certain range of size.

The third one is more reasonable although it is not a biological phenomenon but rather an impact of disappearance of some length class on length structure of the fish staying in the Java Sea. In this case, emigration of certain range of size engender 2 possible biases that caused by a mismatch in drawing growth progression line for estimation purpose:

a. Concerning the first bias, a length class or cohort totally emigrates from the Java Sea (Figure 5) makes growth line tending to pass at smaller size in order to achieved the best growth progression following the criteria defined in the algorithm of ELEFAN (Figure 6). Finally, the estimate of $L_{\propto}$ tends to be smaller and $K$ to be higher, due to steeper growth line as consequent of an absence of large size.

b. In the second one, part of fish (i.e. some length class, usually the large size) emigrates to other area which causes the mean length of the rest tends to be smaller. The high score (explained sum of peak) of initial length frequency distribution as indicated in the first time period of incoming recruits will tend to force the growth line to pass through length class. And the drop off in number of large individuals reduces the mean size of the samples. This gives lower $\mathrm{K}$ and $L_{\propto}$ estimates, because the mean sizes of large groups are reduced and the growth line automatically flattens.

Unfortunately, no data of groups of fishes that emigrated from the Java Sea are available in this study. However, accepting a fragile assumption that the data originating from whole population will arrive at a conclusion that seasonally oscilating growth merely caused by biological phenomena. This assumption was commonly used in previous studies Widodo, 1988; Suwarso et al., 1995; Sadhotomo \& Atmaja, 1985; Dwiponggo et al., 1986). In reanalysing the $D$. russellii data of Widodo (1988) using a stochastic model, Sullivan et al. (1990) showed a high different of estimated value reflecting the seasonal growth pattern of the young recruits. However, their results cannot be used to extrapolate the growth of older fish.

\section{Reproduction and Recruitment}

Preliminary studies on reproductive biology of scads had been pioneered by Delsman (1926) on the early life stage, de Jong (1940) on eggs size distribution of some pelagic species. During the period after war until recent year, there was no meaningful investigation on reproduction conducted in the Java Sea. In last decade, several investigation have been conducted with wider scope. Some reproductive aspect with management proposal was given by Widodo (1988) for both species of Decapterus, Nurhakim 


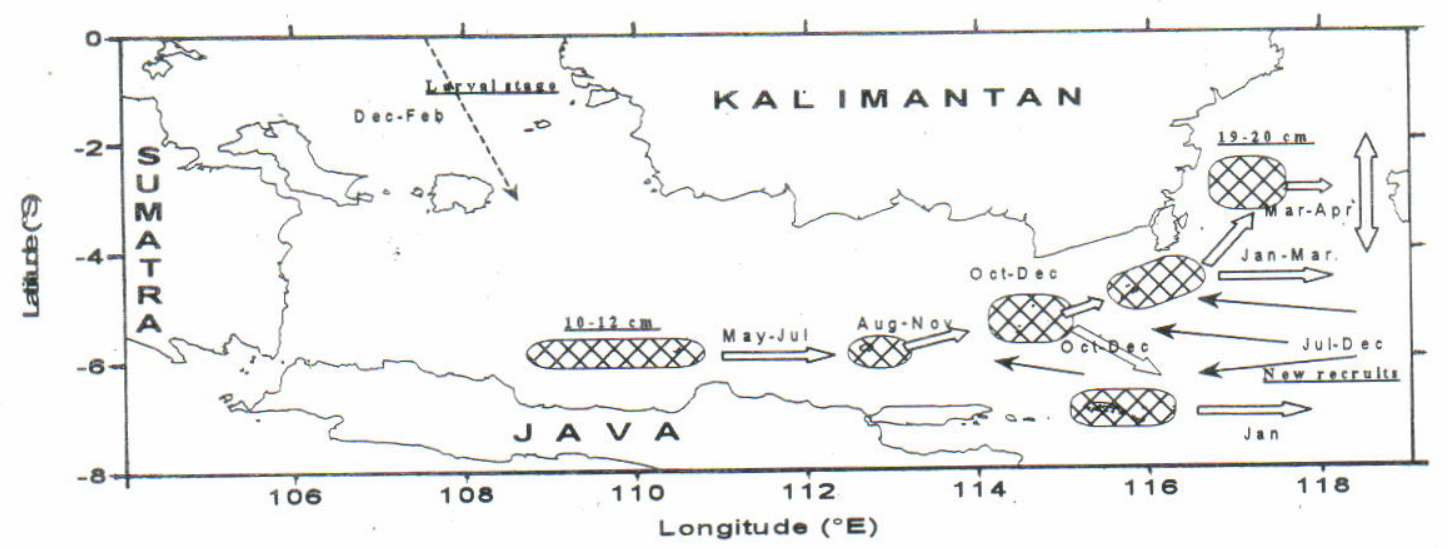

Figure 5. Schematic diagram showing the internal migration inside the Java Sea and possible mixing with new recruit entering this area during the Southeast monsoon.

Remarks: $\rightarrow$ new recruits, $\Rightarrow$ :direction of emigration
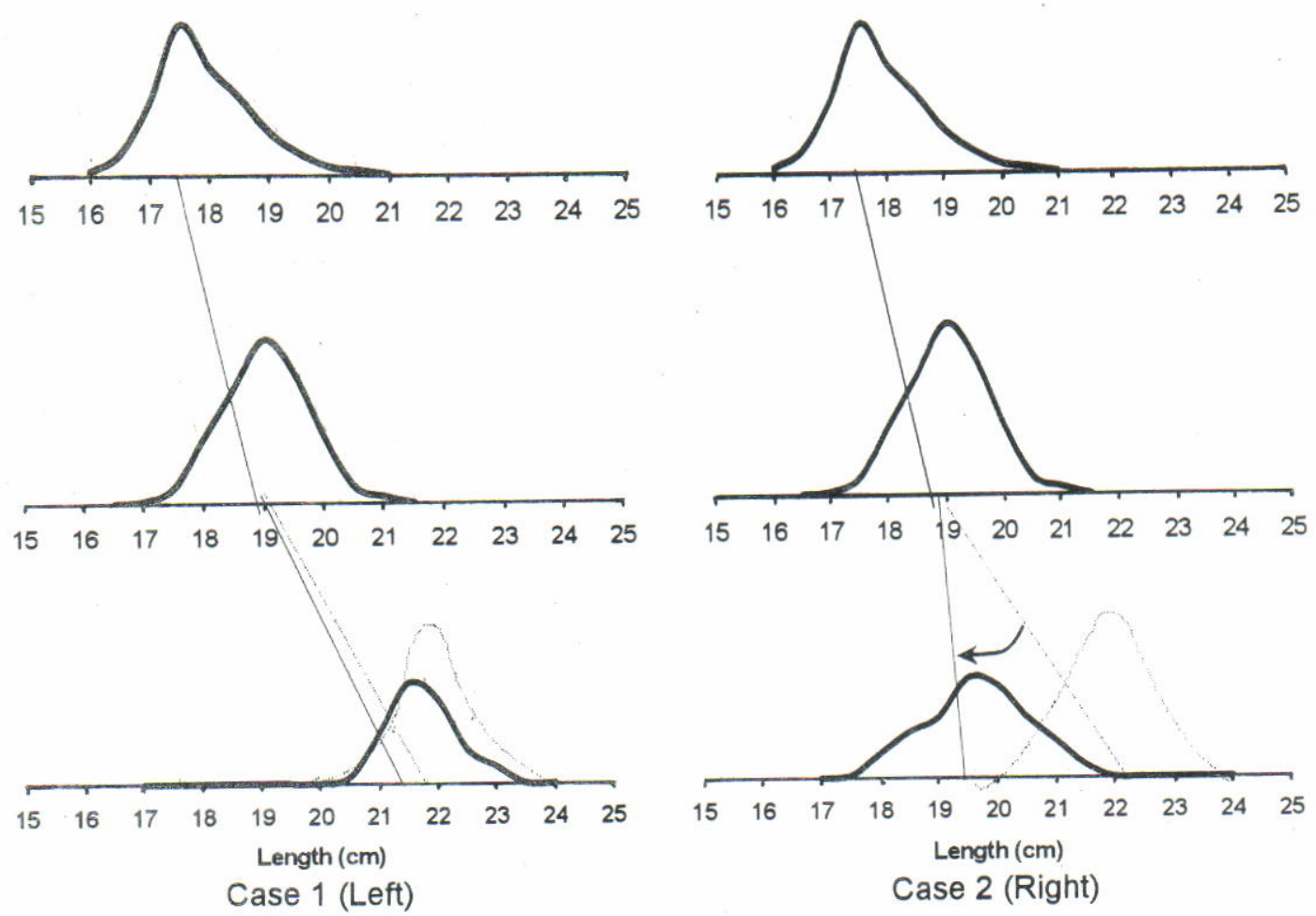

Case 2 (Right)

Figure 6. Illustration of the effect of migration on determination of growth progression (dot histograms are derived from emigrator, solid lines are growth progression line after emigration of one or part of cohort).

(1993) for R. kanagurta. But the most detailed observations was presented by Atmaja et al. (1995) for four of the main species.

This part describes some reproduçtion aspects, i.e. stage of maturity, spawning season and size at first maturity of the main species; a part of the data has been analysed and presented in Atmaja et al.(1995). In this study, presentation is more focused in the context to ecological point of view rather than those of the population dynamics.

\section{Sexual Maturity}

\section{Distribution of Gonado Somatic Index}

Structure of maturity stage of female fishes is evaluated using gonado somatic index and a verification for its relationship for the main species is presented in Table 4. Most of these figures are not comparable with results of other studies of the same population. For examples, Nurhakim (1993); Atmaja et al. (1995) applied another type of index that calculated as: 
Table 4. Average values of gonado somatic index by stage of maturity of the main species

\begin{tabular}{ccccccc}
\hline Stages & D. russellii & D. macrosoma & R. kanagurta & A. sirm & S. crumenophthalmus & S. gibbosa \\
\hline II & 0.31 & 0.56 & 0.27 & 0.41 & 0.54 & 0.56 \\
II & 1.18 & 1.02 & 0.49 & 1.48 & 0.56 & 1.84 \\
III & 2.79 & 2.18 & 2.08 & 3.08 & 1.86 & 3.40 \\
IV & 4.89 & 5.34 & 3.64 & 5.42 & 2.98 & 5.34 \\
V & 7.82 & 12.07 & 4.03 & 7.86 & 5.11 & 9.68 \\
VI & 8.24 & 16.27 & 4.78 & 10.86 & $\mathrm{n} / \mathrm{a}$ & \\
VII & 1.40 & n/a & 0.66 & 4.51 & $\mathrm{n} / \mathrm{a}$ & \\
\hline Remarks: "based on five stages: Immature, Early mature, Developing/Mature, Ripe and Spawn-Spent
\end{tabular}

\section{GSI $=\frac{\text { Weight of gonad }}{\text { Length }}$}

The average values of gonado somatic index by maturity stage in this study are higher than those of Widodo (1988) that used almost the same criteria of staging for the two Decapterus. The average value of gonado somatic index of the stage $\mathrm{VI}$ of $D$. russellii and D. macrosoma are 8.24 and $10.7 \%$ respectively comparing with less than 8 and $5 \%$ for the result of his study (as approximated from the graphic presented in his report). Gjøsæter \& Sousa (1983) gave a lower figure for the highest value of gonado somatic index (stage IV of six criteria) for D. russellii of Sofala Bank, Mozambique (i.e. less than $5 \%$ as shown in their figure compared to 7.9 of stage $V$ to VII of our study). For $R$. kanagurta, the average value of this index is $4.8 \%$ for stage $\mathrm{VI}$ compared to $\sim 7.2 \%$ for stage IV (of six criteria) determined by Sousa \& Gislason (1985) in Mozambique. These differences could make any comparison become invalid due to different criteria of staging. The studies in Sofala Bank used six criteria of staging with the maximum index found in stage IV or mature (stage $\mathrm{V}$ and $\mathrm{VI}$ are spawning and fully spent). While the difference with the observation of Widodo (1988) is probably due to the different visual determination. However, we could not infer that different population may have different reproductive charateristic since the criteria and the composition of samples by length (age) used are not comparable.

For the sake of uniformity of staging criteria used in this study, we emphasize on the use of gonado somatic index rather than the stage of maturity in describing the maturity of all main species. However, visual observations were done by team that possibly generates a subjectivity of observation particularly for the stage IV (last maturing) and $V$ (ripe). For this reason we define strictly the mature stage is the condition if the eggs are already translucent (stage $V$ to $V I I$ for five species, stage IV and $V$ for S.gibbosa).

Based on period of occurrence of the highest average value, monthly evolution of gonado somatic index demonstrate two pattern of fluctuations, one peak a year (i.e. D. russellii, D. macrosoma, and $R$. kanagurta) and irregular pattern (i.e. A. sirm, S. crumenophthalmus, and S.gibbosa) (Figure 7). These pattern would indicate trend of spawning season during the periods of observation, although some peaks that clearly shown in the figure came from few specimens only. Unfortunately, we have no information on the development of gonado somatic index from immature stage to spawning stage that enable us to classify the group of spawner for the next spawning. For instance, it is impossible to classify from similar value of gonado somatic index of $A$. sirm observed during six successive months. We used the lowest limit of length class interval of $15 \mathrm{~cm}$ (at mid length of the 14 to $16 \mathrm{~cm}$ class) for the first five species $(D$. russellii, $D$. macrosoma, $R$. kanagurta, $A$. sirm, and S. crumenophthalmus) and $8 \mathrm{~cm}$ (at mid length 7 to $9 \mathrm{~cm}$ class) for S. gibbosa.

However, these criteria are larger than the common size of these species caught by purse seine fishery and those of the length sample. We relegated the specimens below than these criteria because of none of them consisted of mature fishes. As shown in the table, lower limit of size where the female begin to be mature can be determined using minimum value of gonado somatic index for a mature fish. Taking Stage $V$ as the minimum stage for the mature fish, we can see that the midlength of 18 and $13 \mathrm{~cm}$ are the border of which the mature female of the first five species and of $S$. gibbosa can be found.

\section{Length at First Maturity}

Length at first maturity of six main species are estimated by performing mean length of which the female individual considerably mature. This estimator would be analog as the length at which $50 \%$ of the fish are mature. The term of length at first maturity is commonly used in the context of population dynamics and estimated from cummulative frequency distribution. The definition of mature for various literatures were based on 
different criteria. In order to avoid subjectivity of staging and ambiguity of criterium used for mature fish, we prefer to use 2 criteria; the minima values of gonado somatic index and stage of maturity. Some of the minima values are approximately defined for giving a comparison with the average value of gonado somatic index of Stages IV and V.
Also, we define that Stage $V$ (ripe) or above are considered as mature, except for $S$. crumenophthalmus and D. macrosoma of which specimens of Stage VI and VII were unavailable.

Depart from these criteria, estimation of the mean length of the mature female then can be
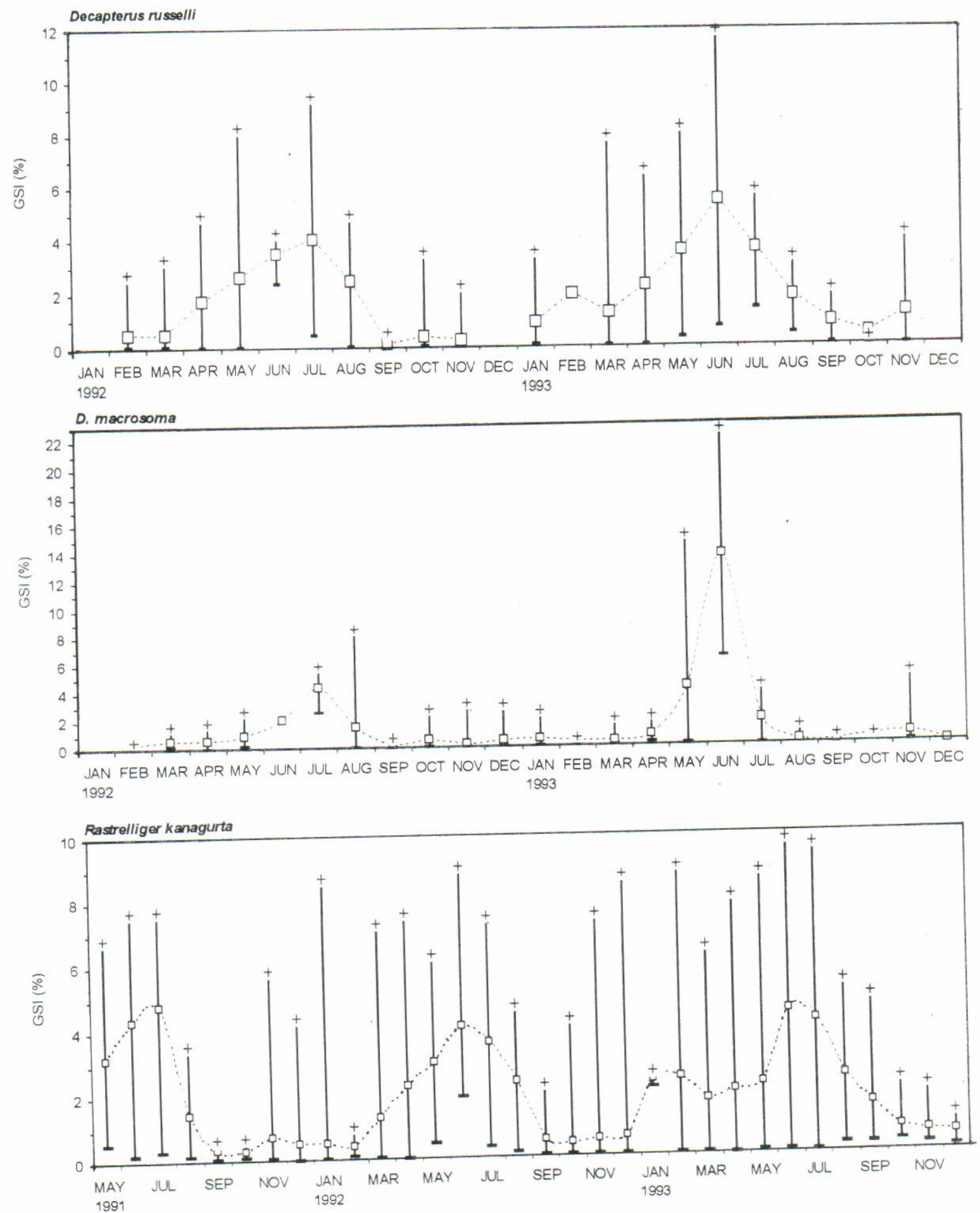

Figure 7a. Monthly evolution of gonado somatic index values of the main species in the Java Sea. Remarks the jointed points are the monthly mean, +'s are the maxima and -'s are the minima 
derived from as the frequency distribution of the mature female. The estimate values appear slightly lower than the result of previous studies from Atmaja et al. (1995); Nurhakim (1993). On other hand, Widodo (1991) estimated the length at first maturity to be much lower than others eventhough the criteria of staging are almost same. Apparently, microscopic verification is needed for determining the mature condition but this procedure is time consuming. For this reason we used transclucent eggs for mature criterium of female of all main species. In this case, subjectivity of observation plays an importance role in influencing the final results, more than the methods applied.
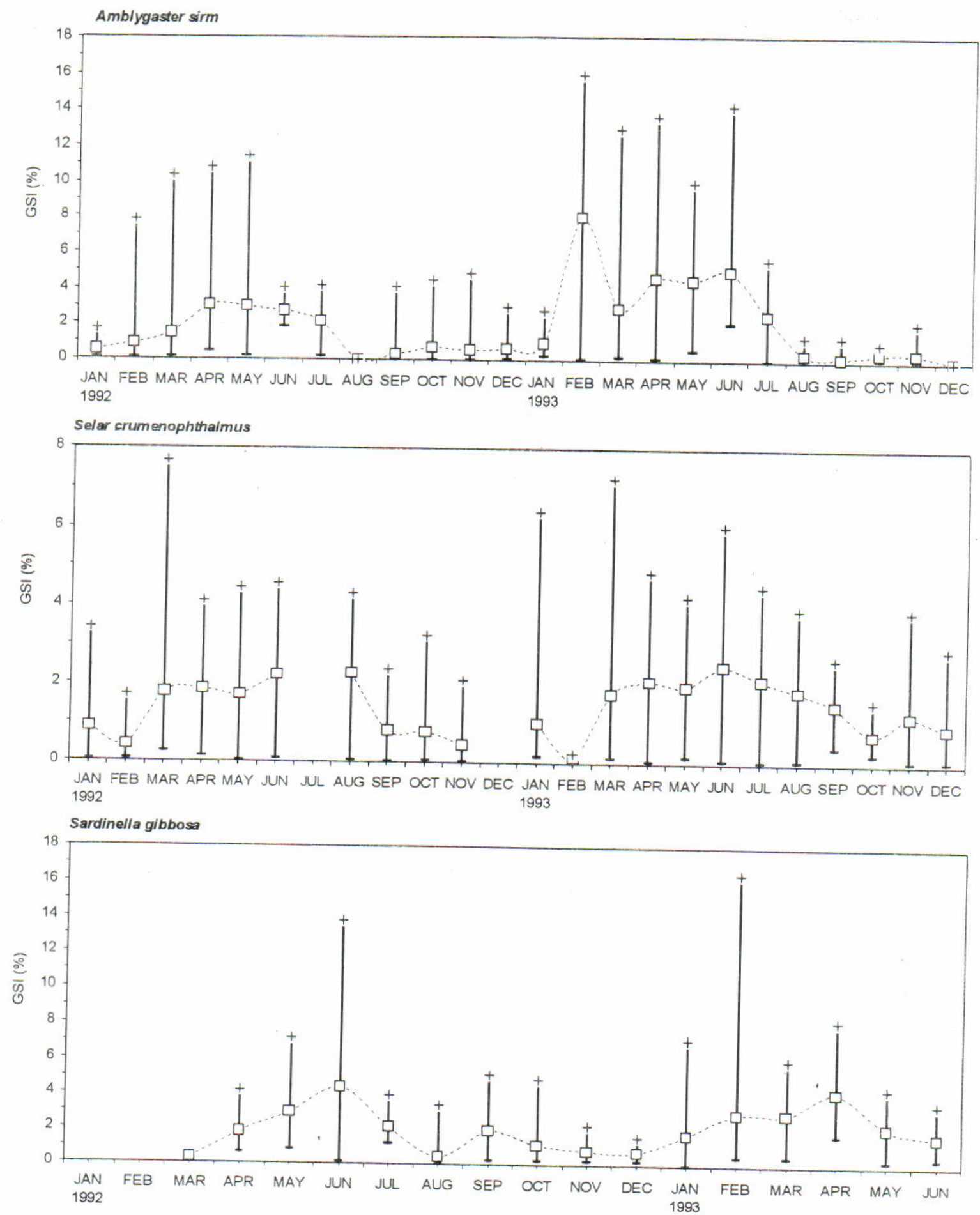

Figure 7b. Monthly evolution of gonado somatic index values of the main species in the Java Sea. Remarks: the jointed points are the monthly mean, +'s are the maxima and -'s are the minima 


\section{Spawning Season}

Recall to Figure 7, the ultimate of spawning season may be predicted from the peaks of the monthly evolution of gonado somatic index as well as, from back calculation of age of juvenile fish entering the fishery at begining recruitments. More precisely, the occurence of spent specimens would give a direct indication of spawning season. Prediction of spawning season also based on summarizing the composition of average gonado somatic index and data sheet for inspecting the occurence of spent specimens.

D. russellii: High value of gonado somatic index or ripe stage are normally found May to July, while spawning period occurs approximately between June to December as indicated by the occurence of partly and fully spent specimens. On December to February, few specimens of resting stage were found in the sample. This stage is marked by residual eggs (dark colour and stuck in ovary wall) left in the ovary and white fat covering the ovary surface.

D. macrosoma: Ripe stage specimens were found in July 1992 and May to June 1993 in the sub area Matasiri-Sambergeleng Bank, while the spent ones (partly and fully) were frequently found in July to August in the more extensive sub areas i.e. Bawean-Lumu-lumu Bank in the southernmost of Makassar Strait. A preliminary conclusion can be drawn for spawning behaviour of $D$. macrosoma. It appears that spawning take place in the near slope ground or probably beyond the Java Sea.

$R$. kanagurta: Similar trend is exhibited with same period of occurence of ripe stage, with the spent specimens found in September to December.

S. crumenophthalmus: Ripe stages were very rarely found in the Java Sea, only few mature fishes found in March, but in general that did not significantly reflect the occurence of spawning. Also monthly distribution of gonado somatic index performs an irregular pattern without strong peak with higher average of gonado somatic index appearing in June and July.

S. gibbosa: Two peaks of average value of gonado somatic index in June and April did not clearly describe the period of spawning. There were no clear indication that spawning corresponding to the second period. Irregular pattern was also performed by gonado somatic index distribution by length interval.

\section{Sex Ratio}

The proportion of female seem to vary by month for the four main species. Proportions of females of 2 oceanic species (D. macrosoma and A. sirm) tended to pass the male one almost all year (Figure 8). There is no significant conclusion to extract from this figure without evaluating reproductive behaviour and the relationship between female stock and successive recruits. However, these aspects are beyond the scope of this study.

\section{Recruitment}

Description of recruitment pattern is evaluated by projecting length composition of catch of purse seine into time dimension of one year period. We perform the ELEFAN module in the Fisat software. Input data are length frequency by cohort as the same set of data used for growth estmation, length weight relationship (Suwarso et al., 1995), and growth parameter estimates listed in Table 1. This step needs a raising factor by monthly sample derived from ratio catch-calculated weight of sample. We used purse seine catch only with taking an attention that the length frequency do not represent the whole size range in the Java Sea. Small size of fish usually caught by coastal gear such as liftnet (bagan) were absent in the the purse seine catch.

The results (redrawn from output of the software) are presented in Figure 9. Different pattern between various years are markly illustrated by main species of pelagic species. In 1992 or 1993 all of species performed a single strong recruitment. The time of peak of recruitment as estimated using maximum likelihood estimator of Hasselblad method are presented in the Table 6.

For most species, special behaviour of the recruitment pattern is performed by the cohort entering Java Sea May to June 1991 (as so called here Cohort 1991 to 1992). However, different patterns for each species seem to be evidence for some periods. The pattern can be summarized as follow:

1. Decapterus russellii: Two peak of recruitments, one was a major recruitment and another one was a minor one in the years 1991 or 1992 and 1994 or 1995 . Single pulse recruitments were observed in 1993 or 1994 and 1992 or 1993. Slightly different peak of recruitment of the periods were observed.

2. Decapterus macrosoma: Similar tendency with those of $D$. russellii but in different period of peaks. 


\section{Decapterus russelii}

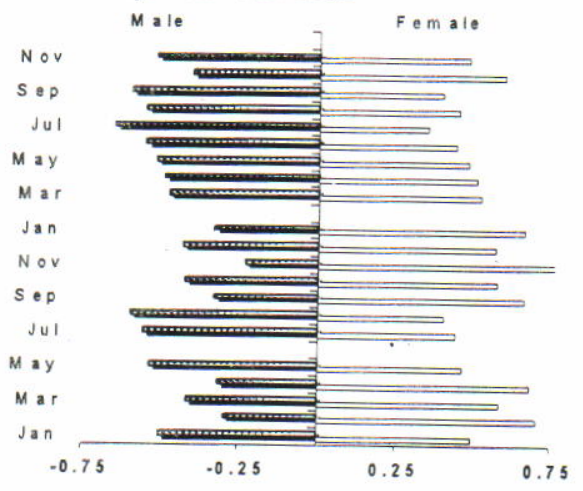

3. Amblygaster sirm

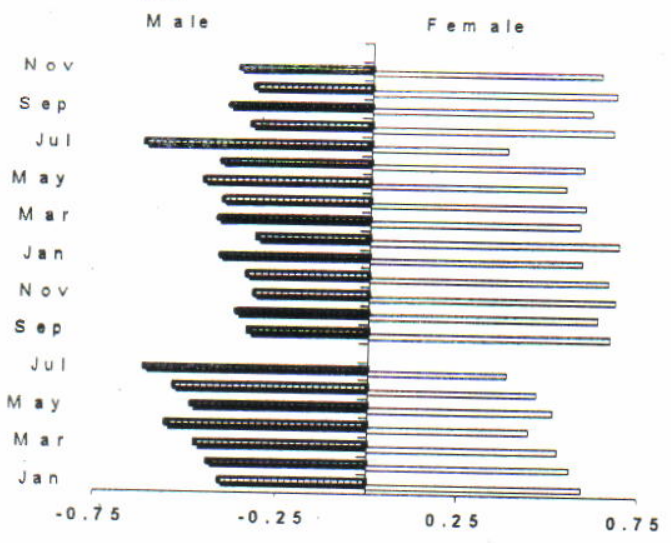

2. Decapterus macrosoma

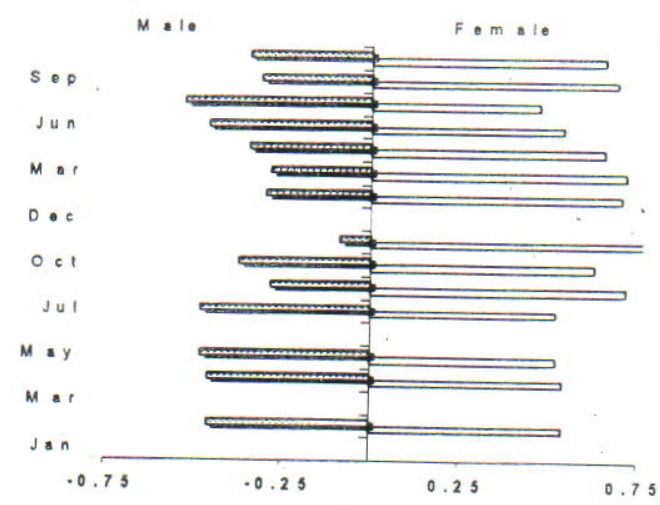

4. Selar crumenophthalmus

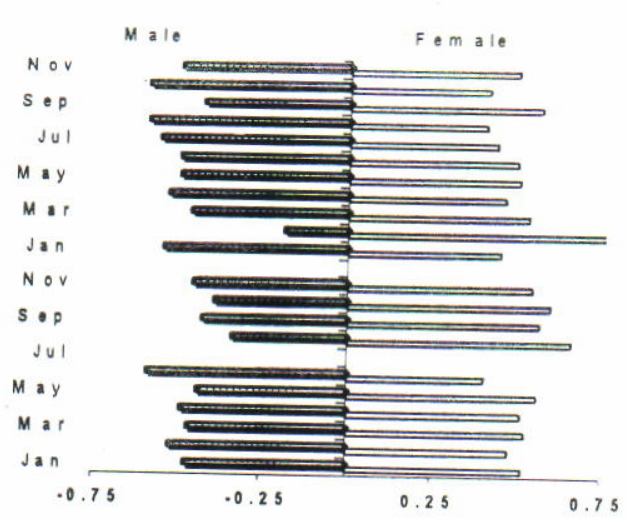

Figure 8. Proportion of gender of four species.

3. Rastrelliger kanagurta: Two peaks of recruitment occured in the period 1993 or 1994 , otherwise, single recruitment with slightly different period of recruitment.

4. Selar crumenophthalmus: Single peak of recruitment occured in 1992 or 1993. While during other periods, two easily distinguished patterns, some of them indicating a strong recruitment, were obviously observed. In the year 1921 or 1992 stronger recruitment appeared in the second period, while in other years occured in the first one.

5. Sardinella gibbosa: Single peak of recruitment exhibited by the data 1993 to 1995 . We do not present the results of other years because of discontinuity of the observations.

It would be interesting to evaluate the recruitment pattern in relation to the evolution of gonado somatic index value. Unfortunately, the year of observation of these aspects were not in the same range of period. But comparison can be done for the period of gonado somatic index observation with recruitment pattern about one year after. We can see that the irregular or non single peak pattern of monthly evolution of gonado somatic index performed by $S$. crumenophthalmus appear to in relation with bi-modal pattern of recruitment, as well as for those of $R$. kanagurta in the year 1993 with recruitment in 1993 or 1994 . The new recruits usually enter the javanese purse seine fishery around May to June, and being fully recruited in the period of September to December. The data input used describing the pattern started from May or June to the next year.

In fact these recruitment patterns did not synchronously follow spawning seasons. Back calculation of age of the average size of cohort firstly enter purse seine fishery would be another way to trace relationship between recruitment and spawning patterns. Calculated age from small size length may be more effective relationship though some of them derived from minor distributions (as shown by underline figures). In general, two period of recruitments can be detected, the major recruitment in May to August and the minor one in November to February.

This would be an auxiliary explanation for the definition of major and minor cohorts as used previously in growth evaluation. As indicated in the table above, most of major recruitment (i.e. more vulnarable to the the fishery) of young fish occured 


\section{D.russellii}

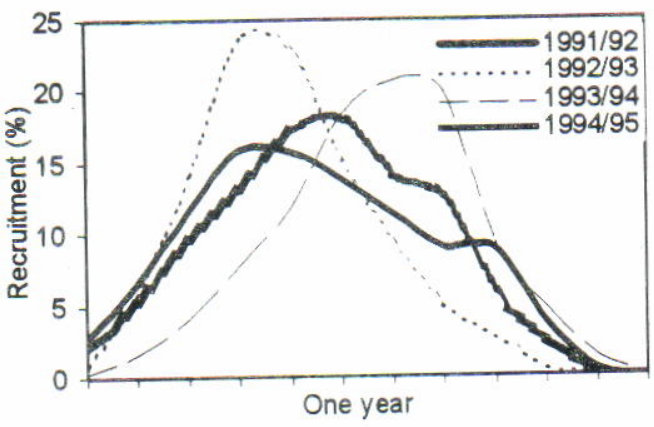

3. R. kanagurta

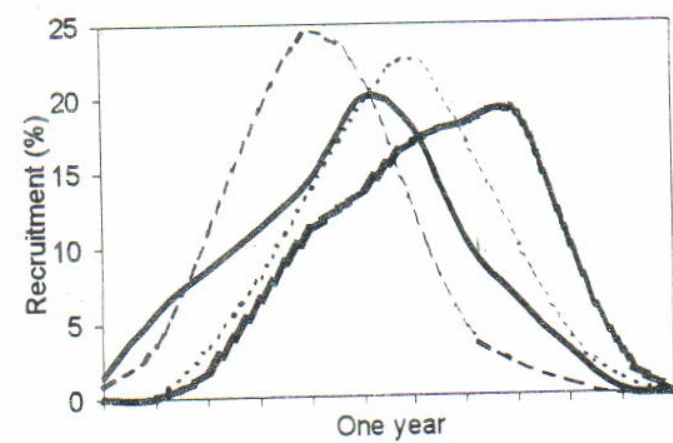

5. S.crumenophthalmus

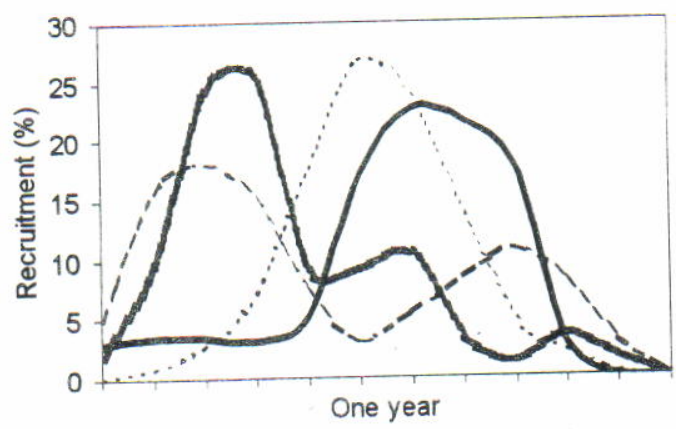

\section{D.macrosoma}

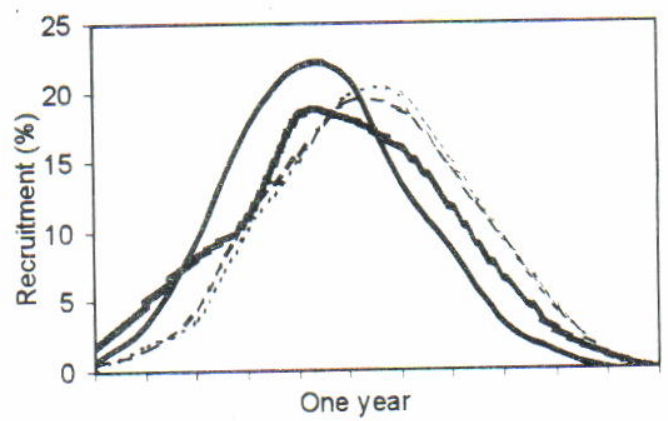

4. A. sirm

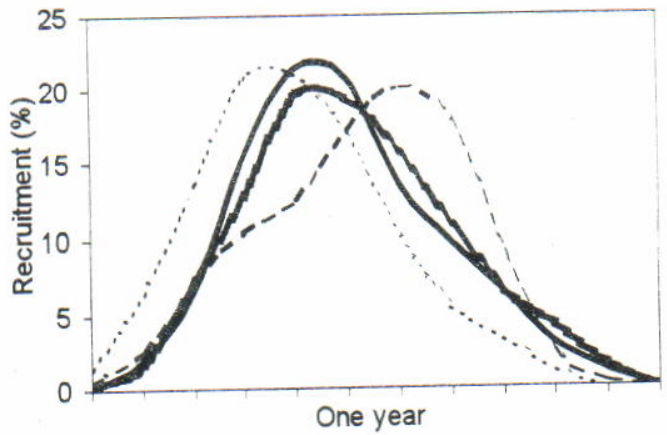

6. S.gibbosa

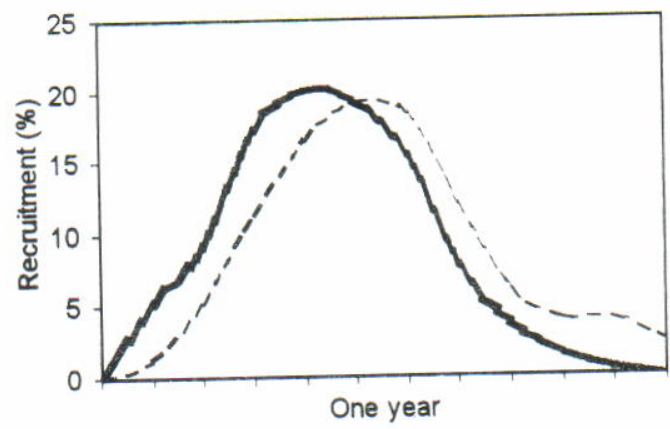

Figure 9. Recruitment pattern of the main species at various years.

in the beginning of Southeast monsoon (June to July) and originated from December to February (Northwest monsoon period) spawning. While the minor recruits were detected entering the fishery in periods of November to March and coming from other period of spawning. An exception seems to appear for S. gibbosa, most of small or young fish may not fully recruit into the Java Sea or out of observation or beyond purse seine fishing ground. However, the occurrence of few young fishes in samples woud be enough to indicate that the period of recruitment of this species to be late one month than others.

\section{Spawning}

Difficulty of finding the mature fish inside the Java Sea (in the area covered by this study) would immediately reveal conclusion that this area is not the spawning ground of the main pelagic species, or at least these species do not spawn in the fishing ground of the purse seine. In relation to recruitment and migration scheme, Sadhotomo \& Potier (1995) implicitely indicated a possible spawning ground of pelagic species (for the highly migrant species, such as $D$. macrosoma) in the slope of eastern part of the Java Sea without 
Table 6. Time of the peaks of recruitment estmated as relative to on year period

\begin{tabular}{lccc}
\hline \multicolumn{1}{c}{ Species } & Years & $\begin{array}{c}\mathbf{1}^{\text {st }} \text { recruitment } \\
\text { (month) }\end{array}$ & $\begin{array}{c}\text { 2 }^{\text {nd }} \text { Recruitment } \\
\text { (month) }\end{array}$ \\
\hline D. russellii: & $1991 / 1992$ & 4.1 & 8.0 \\
& $1992 / 1993$ & 4.6 & 7.3 \\
D. macrosoma: & $1993 / 1994$ & 5.4 & 5.9 \\
& $1994 / 1995$ & 5.6 & \\
R. kanagurta: & $1991 / 1992$ & 2.4 & 8.2 \\
& $1992 / 1993$ & 4.2 & \\
& $1993 / 1994$ & 5.7 & 6.8 \\
S. crumenophthalmus: & $1994 / 1995$ & 7.7 & 6.9 \\
& $1991 / 1992$ & 4.5 & 8.2 \\
& $1992 / 1993$ & 3.6 & 10.2 \\
A. sirm: & $1993 / 1994$ & 5.6 & \\
& $1994 / 1995$ & 1.9 & 6.9 \\
& $1991 / 1992$ & 6.0 & \\
S. gibbosa: & $1992 / 1993$ & 2.6 & \\
& $1993 / 1994$ & 3.6 & 6.2 \\
\hline Remarks: underlined figures are the major recruitments. Month equal 1 means january, etc.
\end{tabular}

giving any detail. However, this hyphothesis means that the most likely spawning ground would be outside of the Java Sea. Delsman (1926) showed an indication of spawning ground of layang $(D$. russellii) near Bawean and Madura Islands in his mission on June 1920 and October 1922.

His statement of observed of fully mature fish in fishermen catch could be unreliable indication for spawning ground as there was no direct observation had been made for determining the maturity. Also, eggs and larvals stages specimens found in that subarea might be misidentified as Caranx kurra and Caranx macrosoma (synonim of $D$. russellii and D. macrosoma). He speculatively used reference of Trachurus trachurus for the genus Caranx (Decapterus) and other genus of Carangidae (that recently identified as genus of Caranx, Atule, Alepes ).

However, a highly seasonal availability of samples in the period before development of purse seine could cause a difficulty in conducting a continous observations on pelagic species in the Java Sea. The phenomena of simultaneous spawning season as indicated in almost the same period of the occurence of the highest average of gonado somatic index of the main species could not be used for corroborating the Delsman's specimens. But, in this case, one could say that the hydrological condition at that time was better than that of current period.

A question of possibility of occurence of spawning ground in the Java Sea in past time would relate to disappearence of substock due to heavy exploitation after 1980's decade and shifting of reproductive regime. Unfortunately, we could not go any further because of the lack of information. Theoretically, an ideal condition in the past (say 30 years ago) can be said as analog with concept of optimal environmental window of Cury \& Roy (1989). Adapting the theory of Gargett (1997), the Java Sea area at that time could be regarded as an area with an optimal window during intermediate stabilities that is a range of stability value for which the associated condition of sea waters (nutrient and others) are sufficient, stimulating levels of primary production which are significantly larger than those of other period. Then, we could speculate that before the tremendous increase of fishing, effort being started in the 1970's decade, the Java Sea stock might be composed by several subpopulations, more than those at recent years. Anyway, the Java Sea is not closed to other neighboring areas and migration of larval and nekton stage could be possible following seasonal circulation scheme of sea water. 
Table 7. Approximates spawning season as back calculated from length at the first period of entering the fishery (with growth parameters listed in Table 1 and to arbitrari' as -1 month; underlined figures are derived from minor distribution)

\begin{tabular}{|c|c|c|c|c|c|}
\hline $\begin{array}{c}\text { Approx. spawning } \\
\text { periods }\end{array}$ & $\begin{array}{c}\text { Modes of } \\
\text { Length }(\mathrm{cm})\end{array}$ & $\begin{array}{c}\text { Periods of } \\
\text { observation }\end{array}$ & $\begin{array}{c}\text { Approx. spawning } \\
\text { periods }\end{array}$ & $\begin{array}{c}\text { Modes of } \\
\text { Length }(\mathrm{cm})\end{array}$ & $\begin{array}{c}\text { Periods of } \\
\text { observation }\end{array}$ \\
\hline \multicolumn{3}{|l|}{ Decapterus russellii } & \multicolumn{3}{|l|}{ Amblygaster sirm } \\
\hline February 1991 & 12.5 & July 1991 & February 1991 & 13.5 & July 1991 \\
\hline February 1992 & 9.5 & June 1992 & January 1992 & 8.5 & May 1992 \\
\hline January 1993 & 10.5 & June 1993 & January 1993 & 9.5 & June 1993 \\
\hline December 1993 & 9.5 & May-June 1994 & December 1993 & 11.5 & May 1994 \\
\hline July 1994 & 8.0 & November 1994 & September 1994 & 9.5 & January 1995 \\
\hline February 1995 & 10.0 & July 1995 & February 1995 & 10.5 & June 1995 \\
\hline \multicolumn{3}{|c|}{ Decapterus macrosoma } & \multicolumn{3}{|c|}{ Selar crumenophthalmus } \\
\hline August 1991 & 8.5 & November 1991 & February 1991 & 9.5 & June 1991 \\
\hline January 1992 & 12.5 & July 1992 & June 1991 & 10.5 & October 1991 \\
\hline January 1993 & 11.5 & June 1993 & September 1991 & $0=$ & $\begin{array}{l}\text { December } \\
1991\end{array}$ \\
\hline February 1994 & 12.5 & June 1994 & Novembe & 8.5 & March 1992 \\
\hline August 1994 & 10.5 & November 1994 & January & 9.5 & May 1992 \\
\hline March 1995 & 9.5 & June 1995 & July 1992 & 9.5 & $\begin{array}{l}\text { November19 } \\
92\end{array}$ \\
\hline \multicolumn{3}{|l|}{ Rastrelliger kanagurta } & March 1993 & 8.5 & \multirow{2}{*}{$\begin{array}{l}\text { June } 1993 \\
\text { September } \\
1993\end{array}$} \\
\hline February 1991 & 11.5 & June 1991 & July 1993 & & \\
\hline February 1992 & 7.5 & May-June 1992 & August 1993 & 8.5 & $\begin{array}{l}\text { November } \\
1993\end{array}$ \\
\hline August 1992 & 8.5 & 1992 & December 1993 & 8.5 & March 1994 \\
\hline Octor & 7.5 & January 1993 & Feb & 9.5 & May 1994 \\
\hline February 1993 & 7.5 & May-June 1993 & September 1994 & 9.5 & $\begin{array}{l}\text { December } \\
1994\end{array}$ \\
\hline \multirow{2}{*}{$\begin{array}{l}\text { August-Sept. } 1993 \\
\text { January } 1994\end{array}$} & 8.5 & Nov.-Dec. 1993 & October 1994 & 9.5 & \multirow{2}{*}{$\begin{array}{l}\text { January } 1995 \\
\text { June-July } \\
1995\end{array}$} \\
\hline & 7.5 & April 199 & April 19 & & \\
\hline March 1994 & 6.5 & June 1994 & August 1995 & 9.5 & $\begin{array}{l}\text { November } \\
1995\end{array}$ \\
\hline May 1994 & 9.5 & nber 1994 & Sardinella gibbosa & & \\
\hline August 1994 & 7.5 & November 1994 & March 1991 & 8.5 & August 1991 \\
\hline November 1994 & 8.5 & January 1995 & November 1992 & 7.5 & March 1993 \\
\hline November 1994 & 9.5 & March 1995 & April 1993 & 7.5 & August 1993 \\
\hline \multirow[t]{2}{*}{ March 1995} & 8.5 & June-July 1995 & November 1993 & 7.5 & April 1994 \\
\hline & & & September 1994 & 8.5 & February1995 \\
\hline
\end{tabular}

\section{Recruitment}

As shown previously, there are 2 periods where group of young fish enter the Java Sea during the beginning Southeast and Northwest monsoon, namely major and minor recruits. For most of species, especially for $D$. russellii, $S$. macrosoma and $A$. sirm, the major recruits correspond to the major cohort that possesing clear growth progression in the Java Sea. It means that most of fishes enter the Java Sea or exactly enter the fishery are born during the period of Northwest spawning season. On other hand, the gonado somatic index data indicate that the mature fishes (stage IV to $\mathrm{VI}$ ) exist in June to July of which spawning season is presumably occured in July to October.

Again, we apply an assumption that most of the mature fishes regularly move to eastward and do spawning outside of the fishing zone. Most of the egg and larva of the related species are pelagic (Delsman, 1926) that the role of the seasonal current in transporting the eggs and larvae is obvious. During period of spawning (July to O.ctober) part of pelagic eggs and larvae are drifted from the spawning ground to the western area, and in November current direction is inverse, and most 
planktonic stage then to be pushed back easterly Some part of those which born in the beginning of spawning season are probably still in the Java Sea and caught by the fishing gear in November to December. In this case, we ignore a possibility of mixture with other progeny from southern of the South China Sea that brought by the current during beginning of Northwest monsoon in NovemberDecember.

\section{CONCLUSION}

In general, the von Bertalanffy growth parameter of the six species can be well estimated using the ELEFAN routine. A caution should be taken in relation to the existing oscillation pattern for the most species and periods that is likely caused by migration of the adult fish. The growth estimates derived from this method successfully traces the pseudo growth progression curve, thus we can notice that the estimated values do not represent the whole stocks. In this case, the emmigration is considered as the more important factor determining the shape of oscillation curve rather than that of the nature somatic growth pattern.

Variability of the Java Sea in 1991 is considered as the the main factor influencing the occurence of additional modal class in the sample sets. More cohorts identified staying in the Java Sea during this anomaly year and they consequently result a higher estimate values of $K$ of certain species.

In general, the fish stock available for the fisheries mainly consist of young fishes, i.e. the average size of the main species are smaller than approximate length at first mature. Very few specimen of adult fish indicate that these groups are not available in the fishing ground, all of the year.

Two groups of recruits are identified in the Java Sea. The major recruits enter the fisheries during the Southeast monsoon (May to August) and the minor ones during December to February. From back calculation of the age of youngest groups of the major recruits, we can conclude that these recruits are not the offsprings descended by the adult fishes stayed in this area in last year period. The peak of maturity of the fishes staying in the Java Sea occurs in June to July, and peak spawning season would be on September, while the approximate spawning of the major recruits is about December to January. The scarce of ripe and spawning stage speciemens in the samples indicate that the spawning grounds of the main pelagic species are not in the Java Sea (i.e. at least these are not in the fishing ground of the purse seine fleets).

\section{Bibliography}

Atmaja, S. B. 1988. Estimation of growth and mortality of round scad (Decapterus macrosoma) in the Java Sea, Indonesia. In Venema, S. C., Christensen, J. M., \& Pauly, D. (eds). Contribution to tropical fisheries biology. FAO, Fish.Rep. 389. 324-345.

Atmaja, S. B., B. Sadhotomo \& Suwarso. 1995. Reproduction of the main small pelagic species. In M. Potier \& S. Nurhakim (eds): Seminar on the Biology, Dynamics, and Exploitations. Java Sea Pelagic Fishery Assessment Project. 69$84 \mathrm{p}$.

Battacharya, C. G. 1967. A simple method of resolution of a distribution into gaussian component. Biometrics. 23. 115-135.

Beverton, R. J. H. \& S. Holts. J. 1957. On the dynamics of exploited fish populations. Fish. Invest., Ser. 2,19. London.

Boely, T., M. Potier. \& B. Sadhotomo. 1994 Evolution and pattern of fishing system: the large purse seiners of the Java Sea. Procciding The Third Asian Fisheries Forum. Singapore. 26-30 October 1992. Asian Fisheries Society. Manila. 270-273 p.

Boely, T., M. Potier, \& S. Nurhakim. 1990. Study on the big purse seine in the Java Sea. VI. Sampling procedure. Journal Marine Fisheries Resources. 47.69-86.

Casselman, J. M. 1987. Determination of age and growth. In Weatherley, A. H. \& H. S. Gill (eds). The biology of fish growth. Academy Press. London. p 209-242.

Cassie, R. M. 1951. Some uses of probability paper for graphical analysis of polymodal frequency distributions. Australian Journal Marine Freshwaters Resources. 5. 513-522.

Cury, P. \& C. Roy. 1989. Optimal environmental window and pelagic fish recruitment succes in upwelling areas. Can. Journal Fisheries Aquatic Science. 46. 670-679.

Delsman, H. C. 1926. Fish larvae and eggs in the Java Sea. 8. Dorosoma chacunda (H.B.) Treubia, Vol.VIII. Livr. 3-4. 
Dwiponggo, A., T. Hariati, S. B. Atmaja, Palomares, M. L. \& D. Pauly. 1986. Growth, mortality, and recruitment of commercially important fishes and penaid shrimp in Indonesia waters. ICLARM Tech. Rep. 17, 91 p.

FAO-ICLARM. 1995. Stock assessment tools (FISAT) user's guide. FAO. Rome

Fontana, A. 1969. Etude de la maturité sexulle des sardinelles, Sardinella eba (Val.) et Sardinella aurita (Cet.V) de la region Pointe-Noire. Cah. ORSTOM (Sér. Océanogr.). 7 (2). 101-114.

Fournier, D. A., J. R. Sibert, J. Majkowski, \& J. Hampton. 1990. MULTIFAN a likelihood-based method for estimating growth parameters and age composition from multiple length frequency data sets illustrated using data for southern blue fin tuna (Thunnus maccoyii). Can. Journal Fisheries Aquatic Sci. 47. 301-317.

Gargett, A. E. 1997. The optimal stability 'window': A mechanism underlying decadal fluctuation in North Pacific salmon stock? Fish. Oceanogr. 6 (2). 109-117.

Gjôsæter, J. \& M. I. Sousa. 1983. Reproduction, age and growth the russell's scad, Decapterus russelli (Rüppell, 1828) (Carangaidae) from Sofala Bank, Mozambique. Rev. Invest. Pesq. Maputo. 8. 83-107.

Gulland, J. A. \& S. J. Holts. 1967. Estimation of growth parameters for data at unequal time intervals. Journal CIEM. 25 (1). 47-49.

Hardenberg, J. D. F. 1938. Preliminary report on a migration of fish in the Java Sea. Treubia, Deel 16, Afl. 2, 295-300 p.

Harding, J. F. 1949. The use of probability paper for graphical analysis of polymodal frequency distribution. Journal Marine Biology Assoc. UK 28. 141-153.

Hasselblad, V. 1966. Estimation of parameters for mixture of normal distribution. Technometrics. $8,431$.

Hempel, G. 1979. Early life history of marine fish (the egg stage). Washington Sea Grant Publication. Seattle. $79 \mathrm{p}$.

Holden, M. J. \& D .F. S. Raitt. 1974. Manual fisheries science. Part 2. Methods of resources investigation and their application. FAO. Fisheries Tech. Pap. Rev. 214 p. lles, T. D. 1984. Allocation of resources to gonad and somatic in Atlantic Herring, Clupea harengus L. In Pott, G. W. \& R. J. Wooton (eds). Fish reproduction, strategy and tactics. Academc Press. London. 322-347.

Ingle, J. \& D. Pauly. 1984. An atlas of the growth, mortality, and recruitment of the Philippines fishes. ICLARM. Tech. Rep. 13. 127 p.

Jong de, J. K. 1940. Preliminary investigation of the spawning habits of some fishes of the Java Sea. Treubia. Deel 17. Afl. 4. 307-330.

Kleiber, P. \& D. Pauly. 1991. Graphical presentations of ELEFAN I. Response Surface. Fish Byte. 2 (9). Dec. 1991.

Matthews, C.P. 1990. The relationship between maximum and asymptotic length in fishes. Fish Byte. 2 (8). Aug. 1990.

Miller, J. P. 1984. The tokology of gabioid fishes. In Pott, G. W. \&. R. J. Wooton (eds) Fish reproduction, strategy, and tactics. Academic Press, London. 119-155 $p$.

Nurhakim, S. 1993. Biologie et dynamique du Banyar Rastrelliger kanagurta (TéléoséenScombridae) dans la pêcherie des grand senneurs en mer de Java. University Bretagne Occidentale. Brest. These doctorat. $106 \mathrm{p}$.

Nurhakim, S. 1995. Population dynamics of ikan banyar (Rastrelliger kanagurta). In Potier, M. \& $\mathrm{S}$. Nurhakim (eds). Seminar on the Biology, Dynamics and Exploitations. Java Sea Pelagic Fishery Assessment Project.

Pauly, D. 1990. Length converted catch curve and seasonal growth of fish. Fish Byte. 3 (8), Dec. 1990.

auly, D. 1985. On improving operation and use of the Elefan program.I. Avoiding drift of $\mathrm{K}$ toward low value. Fish Byte. 3 (3). November 1985.

Pauly, D. \& I. David. 1981. ELEFAN I. A basic program for the extraction of growth parameters from length-frequency data. Meeresfurschungen. 28. 205-211.

Potier, M. \& B. Sadhotomo. 1991. Sampling training. Java Sea Pelagic Fishery Assessment Project. Science Tech. Doc. 4. 29 p.

Potier, M. \& B. Sadhotomo. 1995. Trends in scad fishery of the Java Sea. The Fourth Asian Fisheries Forum. Beijing. October 1995. 
Potier. M. \& B. Sadhotomo. 1995. Exploitation of the large and medium seiners fisheries. In $\mathrm{M}$. Potier \& S. Nurhakim (eds). Seminar on the Biology, Dynamics, and Exploitations. Java Sea Pelagic Fishery Assessment Project.

Sadhotomo, B. \& M. Potier. 1993a. Length composition of the main pelagic species caught by seiners of the Java Sea.1991-1992. Java Sea Pelagic Fishery Assessment Project. AARD-ORSTOM. Sci. Tech. Doc. 15. 171 p.

Sadhotomo, B. \& M. Potier. 1993a. Length composition of the main pelagic species caught by seiners of the Java Sea: 1992. Java Sea Pelagic Fishery Assessment Project. AARDORSTOM. Sci.Tech.Doc. 20. 90 p.

Sadhotomo, B. \& Potier, M. 1994. Length composition of the main pelagic species caught by seiners of the Java Sea: 1993. Java Sea Pelagic Fishery Assessment Project. AARDORSTOM. Sci. Tech.Doc. 27. 102 p.

Sadhotomo, B. \& M. Potier. 1997. Length composition of the main pelagic species caught by seiners of the Java Sea: 1994-1995. Java Sea Pelagic Fishery Assessment Project. AARD-ORSTOM. Sci. Tech. Doc. 23. 124 p.

Sadhotomo, B. \& M. Potier. 1995. Exploratory scheme for migration of pelagic species in the Java Sea. In Potier, M. \& S. Nurhakim (eds). Seminar on the Biology, Dynamics, and Exploitations. Java Sea Pelagic Fishery Assessment Project.

Sadhotomo, B. \& S. B. Atmaja. 1985. On the growth of some small pelagic fish in the Java Sea. Journal Marine Resources Ins. 33. 53-60.

Sadhotomo, B. \& J. R. Durand. 1997. General feature of the Java Sea ecology. Proceeding of Acoustics Seminar Akustikan 2. EU-AARDORSTOM. 43-54 p.

Sadhotomo, B. \& J. Widodo. 1994. Maximum yield estimates for scads fishery in the Java Sea? Proceeding The Third Asian Fishery Forum. Singapore. 26-30 Oct. 1992. Asian Fisheries Society. Manila. 274-276 p.

Shepherd, J. G. 1987. A weakly parametric method for estimating growth parameters from length composition data. In Pauly, D. \& G. R. Morgan. (eds). Length-based methods in fisheries research. ICLARM Conf. Procciding 13. 468 p.

Soriano, M. \& D. Pauly. 1989. A' method for estimating the parameter of a seasonally oscilatting growth curve from growth increment data. Fish Byte. (7)1. March 1989.

Sousa, M. I. \& H. Gislason. 1985. Reproduction, age and growth of the indian mackerel, Rastrelliger kanagurta (Cuvier, 1816) from Sofala Bank, Mozambique. Revista de Investigação Pesqueira, Maputo. 14. 1-28.

Sparre, P. 1991. Estimating of yield per recruit when growth and fishing mortality oscillate seasonally. Fish Byte. 1 (9). Aug. 1991

Sudjastani, T. 1974. The species of Rastreliger in the Java Sea, their taxonomy and morphometry (Percyformes, Scombridae). Marine Resources Indonesian. 16. 1-29.

Sullivan, P. J., H. L. Lai, \& V. F. Gallucci. 1990. A catch-at-length analysis that incorporates a stochastic model of growth. Can. Journal Fisheries Aquatic Science. 47. 184-198.

Suwarso, B. Sadhotomo, \& S. B. Atmaja. 1995. Growth parameters of the main small pelagic species. In Potier; M. \& S. Nurhakim (eds). Seminar on the Biology, Dynamics. and Exploitations. Java Sea Pelagic Fishery Assessment Project.

Wada, T. \& I. Kashiwai. 1991. Change in growth and feeding ground of Japanese sardine with fluctuation in stock abundance. In Kawasaki, T., S. Tanaka, Y. Toba, \& A. Taniguchi (eds). Long-term variability of pelagic fish populations and their environment. Pergamon Press. 181190.

Weatherall. 1986. A new method for estimating growth and mortality parameters from length frequency data. Fish Byte. (4) 1. April 1986.

Widodo, J. 1988a. Population dynamics and management of ikan layang, scad mackerel, Decapterus spp. (Pisces: Carangidae) in the Java Sea. Ph. D thesis. University of Washington. Seattle. $150 \mathrm{p}$.

Widodo, J. 1988b. Population parameters of «ikan layang" Indian scad, Decapterus spp. (Pisces Carangidae) in the Java Sea. Journal Marine Fisheries Resources. 46. 11-44.

Widodo, J. 1991. Maturity and spawning of shortfin scad (Decapterus macrosoma) (Carangaidae) of the Java Sea. Asian Fisheries Science. 4. 245-252. 
.

$\therefore$ 